\title{
Bulanık AHS Yöntemi İle Konteyner Terminalleri İçin RFID Sistemi Seçimi (Selection of RFID System for Container Terminals by Using Fuzzy AHP Method
}

\author{
Serdar ALNIPAK iD a Gülen BILEN ALKAN ${ }^{\text {iD }}$ b \\ a Nişantaşı Üni., İ.İ.B.F, Havacılık Yönetimi (İngilizce) Böl., İstanbul, Türkiye, serdara76@yahoo.com \\ bYüksek Öğretim Denetleme Kurulu Üyesi, Ankara, Türkiye. guleralkan2@yahoo.com
}

\begin{tabular}{|c|c|}
\hline MAK & ZET \\
\hline $\begin{array}{l}\text { Gönderilme Tarihi } 26 \\
\text { Temmuz } 2021 \\
\text { Revizyon Tarihi } 30 \text { Eylül2021 } \\
\text { Kabul Tarihi } 5 \text { Ekim } 2021\end{array}$ & $\begin{array}{l}\text { Amaç - Sürekli gelişim içinde olan bilgi teknolojileri, tüm sektörlerde olduğu gibi konteyner limancılık } \\
\text { sektöründe de rekabet edebilirliğin ve yüksek kalitede hizmet sunmanın en önemli araçlarından } \\
\text { birisidir. Liman/terminal operasyonlarında verimlilik düzeylerini, yüklerin ve liman tesislerinin } \\
\text { güvenliklerini arttırmada bilgi teknolojilerinden sıklıkla yararlanılmaktadır. Bu noktada RFID (Radyo } \\
\text { Frekansı ile Tanımlama) teknolojisi en fazla öne çlkan teknolojilerden birisi olarak görülmektedir. } \\
\text { Sağladığı avantajlar çok çeşitli olsa da bu teknolojinin konteyner terminallerindeki adaptasyonu ve } \\
\text { entegrasyonu yüksek maliyet ve karmaşıklıklar içermektedir. Bu bağlamda RFID teknolojisine yatırım } \\
\text { yapmayı planlayan konteyner terminallerinin optimal RFID uygulamasını seçme kararı stratejik önem } \\
\text { taşımaktadır. Bu teknolojinin konteyner taşımacıllğı ve terminallerinde kullanımı konusundaki } \\
\text { çalışmalar oldukça kısıtlı sayıdadır. Bu çalışmada konteyner terminallerine adapte edilecek RFID } \\
\text { sisteminin seçiminde göz önünde bulundurulması gereken kriterler belirlenerek özgün bir modelin } \\
\text { oluşturulması ve bu model ile farklı RFID sistemlerinin değerlendirilerek ülkemizdeki konteyner } \\
\text { terminallerine en uygun sistemin belirlenmesi amaçlanmıştır. }\end{array}$ \\
\hline
\end{tabular}

Araştırma Makalesi

Yöntem - Belirtilen amaçlar doğrultusunda akademik yazın incelenmiş, konunun uzmanları ile görüşülmüş ve ilgili modele yönelik olarak beş ana ve bunlara bağlı yirmi beş alt kriter belirlenerek BAHS (Bulanık Analitik Hiyerarşi Süreci) yöntemi ile analiz edilmiştir. Analizde kullanılan veriler, bu teknolojiyi incelemiş, bilen ve kullanan Türkiye'deki 3 büyük konteyner terminalinde çalışan uzmanlara uygulanan anketler ile elde edilmiştir.

Bulgular - Ülkemizdeki konteyner terminalleri için en uygun sistem alternatifinin; taşıyıcı araçların ve sürücülerinin RFID etiketleri ile kimliklendirilmesi ve liman kapılarına konacak okuyuculardan sağlanacak verilerden faydalanılması olduğu saptanmıştır.

Tartışma - Bu çalışmada konteyner terminallerinde RFID sistem seçimine yönelik olarak kapsamlı bir model ortaya konulmuş ve oluşturulan model çerçevesinde konteyner terminallerimize en uygun RFID sistem alternatifi belirlenmiştir. Her çalışmada olduğu gibi bu çalışma kapsamında oluşturulan model de şartlar değiştikçe revize edilmelidir. Araştırmanın yapıldığı dönemde ülkemize yönelik olarak ve bu kapsamda bir çalışma bulunmaması nedeni ile yazarlar literatüre mütevazi bir katkı yapmayı ummaktadır.

\section{ARTICLE INFO ABSTRACT}

\section{Keywords:}

RFID Technology

Container Terminal

FAHP

Logistics Management

Received 26 July 2021

Revised 30 September 2021

Accepted 5 October 2021

Article Classification:

Research Article
Purpose - Information technologies, which are in continuous development, are one of the most important tools of competitiveness and high quality service in the container port sector, as in all sectors Information technologies are frequently used in port/terminal operations to increase efficiency levels and security of cargo and port facilities. At this point, RFID (Radio Frequency Identification) technology is seen as one of the most prominent technologies. Although the advantages it provides are diverse, the adaptation and integration of this technology in container terminals involves high costs and complexities. In this context, the decision to choose the optimal RFID application of container terminals that is planned to invest in RFID technology is of strategic importance. Research studies on the use of this technology in container transportation and terminals are very limited. In this study, it is aimed to create a unique model by determining the criteria to be considered in the selection of the RFID system to be adapted to the container terminals, and to determine the most suitable system for the container terminals in our country by evaluating different RFID systems by this model.

Design/methodology/approach - In line with the stated purposes, the academic literature was examined, experts were interviewed, and five main and twenty-five sub-criteria related to the relevant

* Bu çalışma, Dr. Serdar Alnıpak'ın Prof. Dr. Güler Bilen Alkan danışmanlığında yapmış olduğu doktora tez çalışmasından üretilmiştir.

Önerilen Atıf/Suggested Citation

Alnıpak, S., Bilen Alkan G., (2021). Bulanık AHS Yöntemi İle Konteyner Terminalleri İçin RFID Sistemi Seçimi , İşletme Araştırmaları Dergisi, 13 (4), 3889-3909. 
model were determined and analyzed with the FAHS (Fuzzy Analytical Hierarchy Process) method. The data used in the analysis were obtained through questionnaires applied to experts working at 3 large container terminals in Turkey who studied, knew and used this technology.

Findings - It has been determined that the most suitable system alternative for the container terminals in our country is to identify the carrier vehicles and their drivers with RFID tags and to benefit from the data obtained from the readers to be placed at the port gates.

Discussion: In this study, a comprehensive model for RFID system selection in container terminals has been presented and the most suitable RFID system alternative for our container terminals has been determined within the framework of the model created. As in every study, the model created within the scope of this study should be revised as the conditions change. The authors hope to make a modest contribution to the literature, since there is no study for our country in this context at the time of the research process.

\section{Giriş}

Bilgi teknolojileri akıl almaz bir hız ile gelişmektedir. Bu gelişim her sektörü olduğu gibi konteyner taşımacılığını ve terminallerini/limanlarını da etkilemektedir. Rekabet edebilirliğin ve yüksek kalitede hizmet sunmanın büyük önem taşıdığı günümüz iş ortamında, liman/terminal operasyonlarında verimlilik düzeylerini, yüklerin ve liman tesislerinin güvenliklerini arttırmada RFID teknolojisi en fazla öne çıkan teknolojilerden birisi olarak görülmektedir. RFID teknolojisi, radyo frekansları vasıtası ile sabit ve/veya hareketli canlı ve objeleri tekli ve/veya çoklu olarak tanımlamakta kullanılan bir teknoloji türüdür (Alnıpak, 2021:1614). Taşıma amaçlı araçların, süreçlerde kullanılan ekipmanların, yüklerin ve insanların gerek otomatik gerek ise de hatasız olarak verilerini toplayabilen bir yapıda olması nedeni ile liman/terminal süreç ve operasyonlarının nerede ise tamamında kimliklendirme (tanımlama), takip ve güvenlik açılarından fayda sağlayabilmektedir. Ancak bu teknolojinin bazı dezavantajları da bulunmaktadır. Özellikle bu teknolojinin bahsedilen sektörde kullanımının henüz istenilen seviyede yaygınlaşmaması ve mevcut şartlarda yüksek maliyetlerde yatırımlar gerektirmesi en önemli dezavantajlarındandır. Ayrıca standartizasyon ve entegrasyona yönelik bazı sorunlar, sektörün aktörlerini ve özellikle terminal yöneticilerini karar verme aşamalarında zorlamaktadır.

Bu teknolojinin yoğun kullanıldığı depolama, perakendecilik, kütüphanecilik vb alanlarda çok miktarda akademik çalışma bulunmasına olmasına rağmen konteyner taşımacılığı ve terminallerinde kullanımına yönelik araştırmalar oldukça azdır. Bu bağlamda görülmektedir ki pek çok önemli ve dünya çapında limanda kullanılan ve konteyner terminallerinde geleceğin teknolojisi olarak görülen RFID teknolojisinin; belirlenecek kriterler doğrultusunda optimum uygulama modunun belirlenmesi büyük önem taşımaktadır. Çünkü bu teknoloji pahalı bir teknolojidir ve terminal için en uygun modun (kullanım alanının) seçimi pek çok israfın önüne geçecektir. Ayrıca akademik literatürde bu konuya yönelik yeterli sayıda model ve uygulama ortaya konulmamış olması, bu hususta ciddi bir ihtiyaç olduğunu göstermektedir. Bu çalışmada yukarıda belirtilen ihtiyaçlara yönelik olarak; RFID teknolojisi hakkında bilgi ve tecrübe sahibi 3 Türk konteyner limanında, 24 uzman ile yüz yüze yapılan görüşmeler ve diğer sektörlere yönelik olarak bu konuda yapılmış akademik literatürün incelenmesi sonucunda belirlenen ana ve alt kriterler doğrultusunda 5 ana ve bunlara bağlı 25 alt kriter ile özgün bir model oluşturulmuş ve bu model doğrultusunda Türk konteyner terminallerine en uygun RFID uygulamasının belirlenmesi amaçlanmıştır.

\section{Kavramsal Çerçeve}

\subsection{RFID Teknolojisi}

Radyo frekansları vasıtası ile sabit ve/veya hareketli canlı ve objeleri tekli ve/veya çoklu olarak tanımlamakta kullanılan RFID teknolojisi temelde bir Auto-ID (Otomatik Tanıma/Veri Toplama - OT/VT) sistemidir (Özmen ve Birgün, 2011:81-88; Alnıpak vd.,2017). Bu sistem şunlardan oluşur: belli bir ürüne tahsis edilen tekil bir tanıma numarası, ürüne tekil tanıma numarasını depolayabilen bir çip ile eklenen bir kimlik etiketi, çeşitli etiketlerden yüksek hızla sinyal toplama ve bu veriyi ön işlemeye tabi tutma yeteneğine sahip ağlandırılmış RFID okuyucular ve veri işleme sistemleri ile ürün bilgisini depolayan bir ya da daha fazla ağlandırılmış veritabanı (Mcfarlane ve Sheffi, 2003:1-17). RFID dışında 4 adet daha otomatik tanıma sistemi vardır. Bunlar; akıllı kart sistemi, optik karakter tanıma (OCR), barkod ve biyometrik kimlik doğrulama sistemleridir (Üstündağ, 2008; Tuğaç, 2007; Akcayol vd., 2005; Ünlü, 2007). RFID teknolojisi, fiziksel bağlantı ya da 


\section{S. Alnıpak- G. Bilen Alkan 13/4 (2021) 3889-3909}

barkodlarda olduğu gibi optik teknolojilerin gerektirdiği görüş hattı olmadan bilgi aktarımı yapabilen kablosuz bir teknolojidir (Karkkainen,2002:242-252). Bu teknoloji; hayvancilik ve hayvan takibi, havacilik sektörü, inşaat sektörü, tekstil sektörü, sağllk sektörü, kütüphanecilik ve müzecilik, lojistik ve tedarik zinciri yönetimi, madencilik, katı atık yönetimi, perakendecilik, savunma sektörü, ödeme sistemleri, üretim sektörü vb. pek çok alanda kullanılmaktadır (Ngai vd.,2008:510-520). RFID tabanlı sistemlerin nerede ise tamamı şu 4 frekans bandından birinde çalışmaktadır; Düşük Frekans (Low Frequency), Yüksek Frekans (High Frequency), Ultra Yüksek Frekans (Ultra High Frequency) ve Mikrodalga (Alnıpak vd.,2017). Düşük frekans RFID sistemleri genellikle $125 \mathrm{KHz}$ 'de çalışır, ancak $134 \mathrm{KHz}$ 'de çalışan sistemler de bulunmaktadır. Bu frekans bandı, daha yüksek frekanslara kıyasla daha kısa bir okuma aralığ 1 ( $<0.5 \mathrm{~m}$ ya da $1.5 \mathrm{ft})$ ve daha yavaş bir okuma hızı sağlar.Yüksek frekans RFID sistemleri $13.56 \mathrm{MHz}$ 'de çalışır ve LF sistemlerine kıyasla daha geniş bir okuma aralığına ve daha yüksek bir okuma hızına sahiptir. Tipik okuma aralığı 1 metreden daha kısadır. Ultra Yüksek Frekans RFID 860-930 MHz (pasif) bandını (tipik olarak Avrupa'da $868 \mathrm{MHz}$ ve Kuzey Amerika' da $915 \mathrm{MHz}$ ) ve $430 \mathrm{MHz}$ (aktif) bandını kullanır. Okuma aralığı pasif için 6+ metre, aktif $433 \mathrm{MHz}$ de 100 metreye kadardır. Veri transferi hızı HF sistemlerinden hızlı, aşağıda belirtilecek olan mikrodalga frekanslı RFID sistemlerinden ise yavaştır. MF seçeneği ise mikrodalga (2.45 GHz ya da $5.8 \mathrm{GHz}$ ) bandıdır ve en yüksek veri okuma hızına sahiptir. Bu sistem en pahalı olanıdır ve UHF benzeri okuma aralığına sahiptir. Ayrıca, mikrodalga frekanslı sistemler yüksek su ya da metal içeriğe sahip nesnelere nüfuz edemediğinden pek çok uygulama için uygun değildir (Psion Teklogix, 2004). Günümüzde yaygın olarak kullanılan etiketlerin frekansları daha çok HF aralığındadır ve her ülke kendi radyo spektrumunun kullanımını düzenlemektedir (Tuğaç, 2007). RFID tabanlı sistemlerin en önemli belirleyicisi kullanılan etiket tipidir. RFID etiketi, belli kapasitede bir belleğe sahip, taşınabilir yapıdaki parçadır. RFID etiketleri farklı türde ürünlere/yüklere eklenebilmektedir. Etiketler, radyo frekansları vasitasıyla iletilen sorguları alıp, cevap vermeye imkan sağlayan çip, anten ve kaplamadan oluşmaktadır (Banks vd., 2007). Anten, iletişim sağlamak amacıyla radyo dalgaların ileten ve alan parçadır. Anten hem etikete enerji sağlamak için okuyucunun sinyalinden enerji alır hem de okuyucudan aldığı verileri gönderir (Ngai vd., 2008: 510-520). RFID etiketleri güç kaynaklarına ve veri yazma-depolama özelliklerine göre sınıflandırılabilmektedir. RFID etiketleri güç kaynaklarına göre temelde pasif ve aktif etiketler olarak 2 farklı tipte değerlendirilmektedir. Pasif etiket pil içermemekle beraber çipe güç verebilmek ve verileri okuyuculara iletmek için okuyuculardan gelen elektromanyetik dalgaların antende oluşturduğu enerjiyi kullanmaktadır. Haberleşme menzillerinin kısa olması bir dezavantaj olmakla beraber herhangi bir bakıma ihtiyaç duymamaları, basit ve ucuz olmaları avantaj sağlamaktadır (Kavas, 2007). Aktif etiketlerin ise kendi güç kaynakları (genellikle pil) bulunmakta ve bu kaynağı çipi çalıştırmak ve veriyi okuyucuya iletmek için kullanmaktadır. Bir aktif etiket çok düşük düzeydeki sinyallerin alınabilmesini sağlamakta ve okuyucuya iletilecek yüksek düzeyde sinyal üretebilmektedir. Okuyucudan uyandırma sinyali alıncaya kadar, aktif etiket uyku modunda kalmaktadır. (Finkenzeller, 2010). Bu etiketlerin okuma aralıkları pasif etiketlere kıyasla daha uzundur. Ayrıca pil ile çalışmaları nedeni ile sınırlı kullanım sürelerine sahiptirler (Ludvıgsson, 2006). 1 km mesafeye sinyal gönderebilecek kapasitede etiketler de bulunmaktadır. Denizyolu ve demiryolu taşımacılığında özellikle kullanılmakta olan aktif etiketler, GPS (Global Positioning System) ve uydu haberleşme sistemleri ile entegre edilerek monte edildikleri nesnenin izlediği rota üzerinde takibine imkan vermektedir. Pile sahip olmaları nedeni ile bakımlarının yapılması gereken bu piller yüksek maliyetlidirler (Kavas, 2007). Okuyular, sahip oldukları antenler ile kodlu veriyi radyo dalgası formatında etiketlere gönderir ve aktif olmuş etiketlerin geri gönderdiği sinyalleri alırlar. Böylece etiketlerin sahip olduğu veri okunabilmekte ve ayrıca etiketlerin üzerinde yeni veri de yazılabilmektedir. Ayrıca birden fazla frekans aralığında destek verebilmektedirler (Üstündağ, 2008). Uygulamaya bağlı olarak çeşitli tipte okuyucular vardır. Bunlar; harici ya da dahili antenli okuyucu, esnek okuyucu, çoklu-frekans okuyucu, mobil okuyucu, portatif okuyucu vb'dir (Pundir, 2010). Geliştirilen teknolojiler sayesinde RFID okuyucularını daha geniş bir alana yaymak mümkün olmaktadır. RFID okuyucularını bir ağa bağlamak için sıklıkla kullanılan iletişim teknolojilerinden bazıları; Eternet, Ultra Wide Band'ın (Ultra Geniş Band), Wi-Fi / WLAN, ZigBee, GPRS (General Packet Radio Server-Genel Paket Radyo Servisi), UMTS (Universal Mobile Telecommunications System-Evrensel Mobil Telekomünikasyon Sistemi), WiMAX (Worldwide Interoperability for Microwave Access - Mikrodalga Erişimi için Evrensel Uyumluluk), Bluetooth vb'dir (Lieshout vd., 2007). RFID teknolojisi yaygınlaşmaya devam ettikçe global standartlar belirlemeye duyulan ihtiyaç ta artmaktadır. Standart olarak tanımlanmaya en yakın kod, Elektronik Ürün Kodu olan EPC (Electronic Product Code)'dir. EPC dört kısımdan oluşmaktadır. Bunlar; EPC kod versiyonu, üretici / imalatçı bilgisi, ürün tipi, ürünün seri numarasıdır (Üstündağ, 2008). RFID projelerinde özellikle dikkat edilmesi gereken performans kriterleri; 
güvenlik, dayanıklılık, kapsama alanı, okuyucunun okuma kapasitesi, okuyucunun okuma hızı, etiketlerin bilgi depolama kapasitesi ve frekanstır (Ünlü, 2007). RFID uygulamaları çeşitli maliyet kalemlerinden oluşmaktadır. Genel olarak bu kalemler altı kategoriye ayrılmaktadır. Bunlar; donanım maliyetleri, yazılım maliyetleri, sistem entegrasyonu maliyetleri, personel maliyetleri, kurulum hizmetleri maliyetleri ve iş süreci yeniden-mühendisliği maliyetleridir (Banks vd., 2007). Tüm potansiyel ve fiili faydaları ile beraber RFID teknolojisi 4 ana başlıkta belirlenen engele sahiptir. Bunlar; teknik engeller (standart eksikliği, birlikte işlerlik, okuma aralığı, okuma kalitesi, donanımın kilitlenmesi, güvenlik, mevcut sistemle entegrasyon, veri hacmi), kültürel engeller (gizlilik, perakendeciler ve tedarikçiler arasındaki ilişki, çevresel kısıtlar, eğitim eksikliği), finansal engeller ve organizasyonel engeller (yeniden-tasarım süreçleri, yönetilebilirlik)'dir (Shih vd., 2008:58$80)$.

\subsection{Konteyner Terminallerinde RFID Teknolojisinin Kullanımı}

Günümüz lojistik zincirinin önemli bir halkasını limanlar oluşturmaktadır. Uzak mesafelere büyük miktarlarda taşıma yapılmasına imkan sağlayan denizyolu taşımacılığının önemli bir parçasını konteyner taşımacılığı oluşturmaktadır. Bu noktada konteyner limanları/terminalleri artan talebe bağlı olarak kapasitelerini arttırmakta ve bu kapasitelerini etkin, kullanabilmek adına teknolojiye ciddi boyutlarda yatırım yapmaktadır (Erdal, 2008). Yoğun rekabet ortamında bir konteyner terminali, güvenilirliğini ve rekabetçi gücünü arttırmak için terminal operasyonlarının verimliliğine odaklanmalı; yeni teknolojilerin etkilerini analiz etmelidir (Choi vd., 2007: 372-376). Verimlilik, etkinlik ve güvenlik açılarından RFID teknolojisi terminaller tarafından artan oranda tercih edilmektedir. RFID teknolojisi geleceğin limanlarında zorunlu bir teknoloji olarak kabul edilmektedir (Banks vd., 2007). Son dönemlerde hızla artan konteyner taşımacılığı limanlardaki altyapıların da modernizasyonunu gerekli kılmaktadır. Ancak ayn hızla ilerleme kaydedemeyen limanlarda süreçlerin yönetiminde problemler (gemilerin çok fazla bekletilmesi, yetersiz terminal üretkenliği ve verimliliği, tesisin her alanında yaşanan trafik sıkışıklıkları, gümrük vb. kontrollerde yaşanan zaman kayıpları, liman paydaşları ile yetersiz iletişim ve bilgi aktarımına bağlı koordinasyonsuzluk vb) yaşamaktadır (Tsilingiris vd., 2007). Panayides (2007)'de denizcilik sektöründe yapılan ankete göre; elektronik veri değişim (Electronic Data Interchange- EDI) kullanımı, izleme ve takip sistemleri ile tedarik zinciri entegrasyon sistemleri denizcilik sektörünün öncelikli olarak ilgilendikleri ve bekledikleri küresel eğilimlerdir. Ayrıca artan trafiğe bağlı ek güvenlik ihtiyaçları, kapasite ve verimlilik sorunları, etkin intermodal taşımacılık ihtiyacı ve yetersiz otomatizasyon limanları/terminalleri RFID tabanlı sistemleri kullanmaya zorlamaktadır. Entegrasyonu hızla artan bu sistemlerde aktif ve pasif etiketler hibrid olarak kullanılabilmektedir. Aktif etiketler $433 \mathrm{MHz}$ frekanslı iken pasifler $900 \mathrm{MHz}$ frekanslıdır. Konteynere eklenen aktif etiketler ISO 17363 standartlarında üretilir ve üzerlerine defalarca veri yazımı yapılabilmektedir. Konteynere eklenen pasif etiketler ise ISO 10374.2 standartlarında üretilmektedir. Etiketlerin okunmasında genellikle UHF ve MF okuyucular kullanılmakta ve okuyucular liman giriş-çıkış kapıları, rıhtım alanları, depolama ve istif sahaları gibi kontrol noktalarına konumlandırılmaktadır. Etiketlerin veri kapasitelerine ve hangi nesneye (taşıyıcı araç, konteyner, vinç vb.) konulacağına bağlı olmakla beraber etiketler üzerlerinde konteynerlerin numara, konum, ağırlık, taşıdığı yük türü, tehlikeli madde, mühür kontrol, hasar tespit, boş konteyner tespit, taşıyıcı araç, araç şoförü, taşıyıcı araç konum, konteyner elleçleme ekipmanı (vinç, iç taşıma aracı, vagon, forklift vb.) vb verilerini taşıyabilmektedir (Abajo, 2009; Alnıpak, 2021). Konteyner terminallerindeki uygulamalar incelendiğinde, RFID tabanlı sistemlerin temelde konteynerler, yüklemeboşaltma ve taşıma süreçlerinde kullanılan liman içi ve dışı araç/ekipmanlar ve süreçte görevli insanlar için kullanıldığı görülmektedir. Bu uygulamalardaki temel amaçlar; kimliklendirme (tespit) ve takip ile liman ve yük bazlı güvenliğin sağlanmasıdır. Tsilingiris vd. (2007)'e göre konteyner takibinin 3 temel amacı hatasız ve hızlı olarak; konteyner kimlik (ID) tespitinin yapılması, mühür kontrolü ve hasar kontrolüdür. Genellikle konteyner kimlik kontrolü çalışanlar tarafından direkt veya video kontrolü ile gerçekleştirilmektedir. Her iki durumda da insan müdahalesi bulunmaktadır. Ayrıca OCR sistemleri de konteyner kimlik tespitinde kullanılabilmektedir. Günümüzde konteynerlere, araç ve ekipmanlara eklenmiş etiketlerin içerdiği veri tam doğruluk ve otomatik olarak liman içi ve dışına kurulu okuyucular tarafından okunmakta ve kablosuz ağ vb teknolojiler vasıtası ile ilgili sistemlere iletilebilmektedir. Konteynerlere eklenecek etiketlerin türüne (aktif, GPS'li, sensörlü, uydu iletişimli vb) bağlı olarak konteynerlerin lokasyon, içerik, alıcı, gönderen, varış limanı $\mathrm{vb}$ bilgileri kesintisiz olarak takip edilip, raporlanabilmektedir. Ayrıca filo ve terminal saha yönetimi süreçlerinde kullanılan ekipmanların (kreynler, traktörler, mobl vinçler vb) etiketlendirilmesi yaygınlaşmaktadır. Terminal içi alanlara, kapılara ve diğer giriş noktalarına yerleştirilen okuyucular 


\section{S. Alnıpak- G. Bilen Alkan 13/4 (2021) 3889-3909}

kullanılarak hangi taşıyıcı veya konteynerin, hangi zaman dilimlerinde giriş çıkış yaptıklarını ve konumlarını net olarak belirlemek ve operasyonel verimliliği arttırmak mümkün olabilmektedir. Oluşan acil durumların ekranlar vasıtası ile takibi ve tespiti acil reaksiyon ve çözüm sürelerini azaltmaktadır. Bu avantajların yanısıra etiketlendirilmiş nesnelerin ve insanların biribirleri ile hatasız eşleştirilmesi; doğru insan-doğru araç kullanımını ve doğru araç-doğru konteyner taşımasını tam kesinlikle sağlayarak tedarik zincirinin güvenliğine ve etkinliğine katkı sağlamaktadır. Terminallerin güvenliğini sağlamak amacıyla, belirli alanlarda sadece yetkili personellerin bulunmasının sağlanması önemlidir. Bu noktada, personel için akıllı RFID kimlik kartlarının kullanımı, bu güvenliği sağlamada önemli bir araç olarak kullanılmaktadır. Temassız akıllı kartlar ile sadece giriş bilgileri (vardiya, iş tanımı, izin verilen araçlar vb.) değil ek olarak fotoğraf gibi biometrik bilgiler de saklanabilmektedir. Güvenlik noktalarında kartın içindeki fotoğraf bilgisi sayesinde sahtekarlık teşebbüsleri önemli ölçüde azaltılabilmektedir. Tenha giriş noktalarında, kapalı devre televizyonlar (CCTV) personel ile kartta mevcut bulunan çalışanın resmini eşleştirerek kontrol yapabilmektedir (Mullen, 2005:181182). Her yıl dünyada milyonlarca konteyner dolaşımdadır ve yüzlerce limanda milyonlarca konteyner hareket halindedir. Bu hacmin sadece \%2'si güvenlik incelemesine tabi tutulurken, boş konteynerlerde bu oran da tutturulamamaktadır. Bu hacimde bir ticarete yönelebilecek terör eylemleri tüm ticareti sekteye uğratacaktır. Terör, taşınan yüklere yönelik hırsızlık teşebbüsleri, kaçakçılık vb riskler ticareti tehdit altında bırakmaktadır (Narsoo ve Sunhaloo, 2009: 127-142). Konteynerler; nükleer silah, radyoaktif madde ve konvansiyonel silah kaçakçılığı, ilaç kaçakçılığı, insan kaçakçılı̆̆ı, nükleer, radyoaktif, kimyasal ve biyolojik madde bulaştırma, hırsızlık, tehlikeli madde içeren konteynerlere zarar verme (patlatma veya sızdırtma) vb tehlikelere maruz kalabilmektedir (Tsilingiris vd., 2006). Konteyner taşıma güvenliğini arttırmaya yönelik olarak önemli girişimler ve düzenlemeler yapılmaktadır. Bunların başında eskiden beri kullanılan mühür (seal) kullanımını geliştirme çalışmaları gelmektedir. Mühür, konteynerin tek veya her bir kapısına takılan ve içeriye girişi engelleyen ekipmandır. Bu mühürlerin kırılması ve değiştirilmesi durumları göz kontrolleriyle sağlanmaktadır. Kırılan bir mührün tespiti durumunda illegal girişimin zamanını, yerini ve kimin tarafından yapıldığını belirlemek çok zordur. Mekanik mühürlerin sıklıkla kullanılması, ucuz ve kullan-at niteliklerine sahip olması sebebiyledir (Werner vd., 2007). Kullanılan diğer mühür türü akıllı mühürler'dir. Akıllı mühürler, işlevsel olarak kapsamlı ve kullanıcıya zeki formda özellikler sunan mühürlerdir. Eklendiği nesnelerin statüleri hakkında veri sağlayan bu tip mühürler denetim ve kontrol süreçlerini kolaylaştırmakta ve hızlandırmaktadır. Mühürler; bu işlemleri entegre edilen farklı teknolojilerin (sensörler, e-imza, RFID, hologram, ssıl ayrışım vb) de yardımı ile sağlamaktadır. Konteyner mühürlerinde RFID tabanlı uygulamaların tipik örneği "E-Mühür"'lerdir (Englert vd., 2007). Bu tip mühürler kullanılacak etiket türüne göre pasif veya aktif olabilmektedir (Rizzo vd., 2011: 846-852). E-mühürler, ISO 18185-1 ve ISO 18585-5 standartlarında üretilmektedir. Genelde $433 \mathrm{MHz}-2.4 \mathrm{GHz}$ frekanslarında çalışmaktadır (Thomas, 2009). Etiketler spesifik ID numarasına sahiptir, taklit edilemez ve değiştirilemezler. Akıllı mühürlerin en büyük avantajlarından birisi kilidin açılması ve/veya yetkisiz olarak yapılan girişlerde uyarıcı sinyaller göndermeleridir. Konteynerler varış noktasına ulaştıııldığında yetkili personeller okuyucuları kullanarak etiketlerdeki verileri okutmakta ve yüklerin tespitini yapmaktadır. Bunlara ek olarak varış öncesi konteynerlerin durum bilgileri gümrük ve liman personellerine iletilebilmektedir (Chung, 2005). E-mühürlü akıllı konteynerlerin kullanımı firmalara "Green Lane (Güvenli Şerit)" hakkından yararlanma avantajını da sağlamaktadır. Bu hak ile firmalar, konteynerlerini gümrükten kontrolsüz olarak geçirebilmekte ve gümrükte kalma sürelerini minimize edebilmektedir. Böylece lojistik maliyetler azalmakta, envanter depolama maliyetleri düşmekte ve müşteri hizmet kalitesi artmaktadır. RFID'li e-mühürler sadece güvenliğe yönelik olarak değil takip ve konumlandırmaya yönelik olarak ta kullanılabilmektedir (Rizzo vd., 2011). Bu tip mühürlere entegre edilecek sensörler vasıtası ile çevresel koşulları (ışık, titreşim, konum, nem, sıcaklık, basınç, kimyasal ajanlar vb) ölçümleyebilmektedir (Englert vd.,2007; Tsilingiris vd., 2006). Tüm taşıma sürecinde bu teknolojilerin vasıtası ile toplanan veriler liman operasyonlarının yönetiminde etkin olarak kullanılabilmektedir. Özellikle liman içi operasyonel planlama, sağlanan veriler ile kolaylaşabilecektir. Ayrıca RFID etiketindeki veriler (yük tipi, miktarı, varış limanı, yükleme tarihi vb) gemi manifestosu ile karşılaştırılarak operasyonel hatalar minimize edilecek, kağıt israfı önlenecek, personel verimliliği ve liman üretimi arttırılabilecektir (Balog vd., 2005). RFID teknolojisi, konteyner terminali kapı giriş çıkışlarında da kullanılabilmektedir. Geleneksel kapı sistemlerinde, kamyon plaka ve konteyner numarasından tanıma, konteyner hasarını tespit etme, konteyner mührünün kontrolü vb. işler kapı görevlileri tarafından manuel olarak yapılmaktadır (Choi vd.,2006). Kapı süreçlerinde; konteyner tespiti, kamyon ve şoför tespiti ve bilgiyi iletme teknolojisindeki eksikler nedeniyle trafik yoğunluğu oluşmakta, boş yere insan gücü harcanmakta ve sonuç olarak terminal sahalarının verimliliği 
düşmektedir (Erdal, 2008). RFID tabanlı kapı sistemleri; etiketlendirilmiş araçları, şoförlerini ve konteynerleri okuyucular vasıtasıyla otomatik olarak tanıma yetkinliğine sahiptir (Choi vd., 2007). Okuyucular vasıtasıyla alınan veriler liman sistemleri ile anında karşılaştırılabilmektedir. Ayrıca konteyner mühürlerinin sağlamlığı etiketlendirilmiş mühürler vasıtasıyla kolaylıkla tespit edilebilmektedir. İlgili işlemler RFID tabanlı sistemler vasıtasıyla çok daha verimli, hızlı ve doğru olarak yapılabilmektedir. RFID tabanlı otomatik terminal kapı sistemlerinin temel yapısı Şekil 1'de gösterilmiştir (Choi vd., 2006: 2155-2163). Günümüzde konteyner terminali giriş kapılarında RFID dışında en sık kullanılan 2 teknoloji OCR (Optical Character RecognitionOptik Karakter Tanıma) ve barkod'dur.

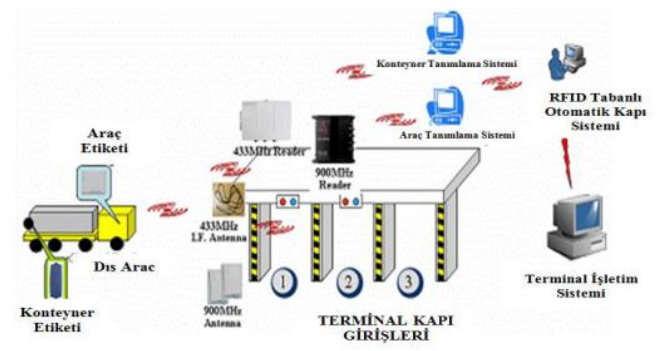

Şekil 1. RFID-Tabanlı Otomatik Terminal Kapı Sistemi

RFID teknolojisinin konteyner terminallerinde sağlayacağı ölçülebilir ve ölçülemeyen faydalar, etiketlerin ve okuyucuların hangi objelerde ve pozisyonlarda kullanılacağına bağlı olarak değişse de gerek bölgesel seviyede gerek ise de küresel seviyede kullanımı ile Tablo 1'de belirtilen faydalar sağlanabilmektedir.

Tablo 1. RFID Teknolojisinin Konteyner Terminallerinde Sağladığı Faydalar

- Tüm süreçlerde otomatik olarak anlık, eksiksiz ve doğru veri sağlanması

- Terminaldeki diğer sistemlere entegre olması ile tüm departmanlar arasındaki veri akışında etkinliğin artış1

- Artan otomatizasyon ile kâğıt işlerinde (paperwork) azalış

- Terminal operasyonlarında; insan, araç ve yüklerin kolay takibi ile etkin süreç yönetimi, artan liman ve yük güvenliği,

- Etkin ve otomatize kapı yönetimine bağlı olarak bekleme sürelerinde azalma, artan emniyet, insan hatalarının minimizasyonu,

- Liman dışı araçların bekleme sürelerinde azalmaya bağlı olarak araç trafiğinde azalış,
- Tüm liman operasyonlarında verimlilik ve etkinlik artışı,

- Kayıp, çalıntı, sahtecilik vb. illegal teşebbüslerde azalmaya bağlı olarak yük ve tedarik zinciri güvenliğinde artış

- Konteyner ve gümrük denetim sürelerinde azalış

- Personel maliyetlerinde azalış,

- Konteyner elleçleme hatalarında azalış,

- Liman konteyner üretiminde artış,

- Terminal sahalarının (depo, rıhtım vb) yönetiminde etkinlik artış1,

- Gemi bekleme sürelerinde azalış,

- Terminal rekabet edebilirliğinde artış,

- Elde edilen otomatik ve doğru veri ile etkin süreç planlaması vb.

Konteyner taşımacılığında RFID teknolojisinin kullanımına yönelik yaşanabilecek sorunlar bulunmaktadır. Bunlar genel olarak; konteyner taşımacılığındaki aktörlerin çekingenliği, standartizasyon eksikleri, yatırımın geri dönüşümündeki belirsizlikler, kanuni düzenlemelerdeki eksiklikler, konteyner endüstrisindeki aktörlerin çeşitliliği, yüksek maliyetler, bilgi paylaşımındaki entegrasyon eksiklikleri olarak tanımlanmaktadır (Tsilingiris vd., 2007; Balog vd., 2005). Yao vd. (2012)'ye göre RFID uygulamalarındaki en büyük engeller; maliyet, veri güvenliğine yönelik çekinceler, olası etkisizlik durumu, radyo dalgalarının karışma olasılığı, üreticiler arasında protokollerle netleştirilmiş standartların olmaması, organizasyonel destek azlığı ve belirsiz yatırım geri dönüş oranı' dır.

\subsection{Literatür Taraması}

RFID teknolojisinin konteyner terminallerinde kullanımı gün geçtikçe artış gösterse de ilgili literatür incelendiğinde kantitatif nitelikte yapılan çalışmaların çok az olduğu görülmektedir. Özellikle bu teknolojinin kullanımına yönelik sağlanabilecek faydalar ve yaşanabilecek zorluklara yönelik çalışmalar oransal olarak öne çıkmaktadır. Balog vd. (2005)'te bir konteyneri taşıma sürecinin tüm aşamalarında takip etmek ve hırsızlık ve/veya terörizmden kaynaklanabilecek hasarları önleyerek konteynerin güvenliğini sağlamak için kullanılabilecek bir takip, onay ve sensör sisteminin kullanılabileceğini belirtmiştir. Tsilingiris vd. (2006)'da 


\section{S. Alnıpak- G. Bilen Alkan 13/4 (2021) 3889-3909}

konteynerlerin güvenlik problemini ele almış ve bu problemin ortadan kaldırılması için RFID'nin (Radyo Frekansıyla Tanımlama)kullanıldığı yenilikçi çözümleri araştırmıştır. Kış ve Kalaycı (2008)'de yaptıkları çalışmada Kablosuz Bilgi Sistemleri için RFID Altyapısı (KABSRA) projesi ve bu altyapının veri toplama süreçlerinde kullanılan açık kaynak kodlu denizcilik belgeleme yazılımı Kumanifest yazılımını açıklamıştır. Englert vd. (2007)'de yakın gelecekte Long Beach ve Los Angeles limanlarında kullanılabilecek RFID tabanlı otomatik konteyner takip ve tanımlama sisteminin güvenlik açıklarını incelemiştir ve etiketlerin güvenliği konusu üzerinde durmuştur. Tsilingiris vd. (2007)'da konteyner taşımacılığındaki aktörleri ve sektörde RFID kullanımını sağlayacak etmenleri ve bu etmenlerin önündeki engelleri irdelemiştir. Park (2006) çalışmasında limanlardaki gemi kalış sürelerini kısaltmayı amaçlayan ve

RFID ile çalışan Gerçek Zamanlı Lokasyon Sistemi'ni (RTLS) analiz etmiştir. Dempsey (2011) yazdığı makalede RFID teknolojisinin limanlarda kullanımına yönelik artış olduğunu ve liman yöneticilerinin özellikle kapılarda ve saha yönetimine yönelik araç takibinde ilgili teknolojiyi tercih ettiklerini belirtmiştir. Hu vd. (2011) çalışmasında konteyner terminal kapılarında RFID tabanlı kontrol sistemi önerisi yaparak, ilgili sistemin araç bekleme sürelerinde ve park yerlerinin doluluğunda azalma sağlayacağını öngörmüştür. Narsoo ve Sunhaloo (2009) çalışması Port Louis limanı için RFID tabanlı bir konteyner izleme sisteminin uygulaması üzerinedir. Bu çalışma için SWOT Analizi ve anket yapılmıştır ve uluslararası düzeylerde çeşitli RFID sistemleri incelendikten ve karşılaştırıldıktan sonra RFID tabanlı bir çözümün limanda uygulanmasının pozitif yönde önemli etkileri olacağı sonucuna varılmıştır. Kim vd (2008), Kore hükümeti sponsorluğunda gerçekleştirilen araştırmasında terminal konteyner deposundaki operasyonların yönetimi için RFID tabanlı bir iş süreci otomasyon sistemi önermişlerdir. Cho vd. (2006) çalışmalarında, LITeTag olarak adlandırılan ve bilgi teknolojisi tabanlı liman lojistiği için kullanılacak bir RFID sisteminin tasarım ve uygulamasını sunmuştur. Bu sistem, üç bölümden oluşmaktadır: akıllı etiket, akıllı elektronik konteyner mührü ve RTLS (gerçek zamanlı konumlama sistemi). Yazarlar, liman yönetimi için yük ve maliyeti düşürmek amacıyla aktif etiketli RFID sistemi önermişlerdir. Temel olarak önerdikleri sistem $433 \mathrm{MHz}$ radyo frekansında çalışmaktadır ve geniş bir iletişim kapsamına sahiptir. Etikeler, konteyner ve paletlere takılmakta ve ISO/IEC18000-7 uluslararası standardına uygunluk göstermektedir. Torres Barro vd. (2010)'da tüm konteyner sahasını kapsayan bir RFID-tabanlı yönetim sistemi yazılım platformu önermişlerdir. Önerdikleri sistemin; takip, etkin rezervasyon ve araç yönetimi, otomatik yükleme planlaması konularında verimli olduğunu ve hataları azaltıcı etkileri olduğunu belirtmişlerdir. Daschkovska ve Reiter (2008) çalışmalarında, limanlardaki gümrük denetimlerinin azaltılmasına ve elektronik mühürlere yapılan yatırımların değerlendirilmesine odaklanmıştır. Farklı tiplerdeki e-Mühürlerin güvenlik performansı üzerindeki etkilerini, limanlardaki gümrük denetimlerini de göz önünde bulundurarak ölçümlemişler ve verimlilik açısından ilgili güvenlik aygıtlarına yapılan yatırımların pozitif etkiler yaratacağınıortaya koymuşlardır. Miragliotta vd. (2007), Kuzey İtalya'da faaliyet gösteren bir limanı baz alarak RFID adaptasyonuna bağlı olarak temel liman aktivitelerindeki performans gelişmelerini 4 senaryo çerçevesinde incelemişlerdir. Bu çalışmaya göre özellikle kapı girişlerinde ve saha yönetiminde maliyetler açısından RFID'in büyük fayda sağlayacağı öngörülmüştür. Yunming vd. (2007) çalışmasında; basit olarak RFID tabanlı konteyner takibine yönelik bir yazılım algoritması tasarlamışlardır. Bu bağlamda, ulusal gümrük takibi merkezi, liman takip merkezi ve araç izleme merkezi ile bütünleştirilmiş bir konteyner izleme altyapısı önerilmiştir. Kim vd. (2004) çalışmasında genel olarak RFID teknolojisinin konteyner terminallerindeki uygulamalarını incelemiş ve terminalin verimliliğini arttırmanın yollarını araştırmışlardır. Sonuçlara göre; RFID teknolojisi ile önceden toplanan araç ve konteyner bilgileri kullanılarak giriş ve depo alanı operasyonlarında verimlilik açısından iyileştirmeler elde edilebileceğini belirtmiştir. Ayrıca aynı çalışmada terminal kapı girişlerinde kullanılacak RFID tabanlı sistemler vasıtasıyla işlem zamanlarının azalacağı ve hatasız veri toplanarak verimliliğin artacağı vurgulanmıştır. Ting vd (2012) çalışmasında RFID tabanlı olarak limanda bulunan iç ve dış tüm araçların takibine yönelik olarak liman yetkililerinin denetiminde test çalışmaları yaparak RFID 'in güvenilirliğini incelemişler ve limanda kullanımını uygun bulan sonuçlar ortaya koymuşlardır. Bu çalışmada araştırmacılar; uzaklık, penetrasyon, hız ve iki etiket arasındaki mesafe olarak 4 parametrenin test edilmesi üzerinde durmuşlardır. Özellikle konteyner sahasında okunurluğun yüksek olduğunu tespit etmişler lakin rıhtım tarafındaki sonuçların geliştirilmesi gerektiği üzerinde durmuşlar ve araçların yer bilgilerinin gerçek zamanlı tespitiyle liman hizmetlerinin optimizasyonunda artış olacağını öngörmüşlerdir. Bu bölümün ilk paragrafında da belirtildiği üzere yazarlar tarafından literatür araştırmasının gerçekleştirildiği süreçte kantitatif çalışmaların çok az 
olduğu ve konteyner terminallerine yönelik olarak bu çalışmamızda oluşturulan kapsamda bir seçim problemi modeline rastlanmamıştır.

\section{Yöntem}

\subsection{Bulanık Analitik Hiyerarşi Süreci}

İlk olarak Lotfi Zadeh tarafından 1965 yılında çalışılan ve üyelik derecesinin 0 ile 1 arasında değişebileceğini ileriye sürerek oluşturulmuş bulanık küme teorisi geniş kapsamda uygulanabilirliği olan bir teoridir. Bulanık küme teorisinde küme aitlik derecesi $(\mu)$ olarak tanımlanmakta ve 0 ile 1 arasında değer almaktadır. Bu teoride $\mu=0$ kesin olarak kümeye ait olmamayı, $\mu=1$ ise kesin olarak kümeye ait olmayı yani üyeliği ifade etmektedir. Bir çok karar verme problemi bulanıklık içermektedir. Çözülmek istenen problem belirsizlik içermekte ise bu belirsizlik tolere edilebilmelidir. Bu açıdan Bulanık AHS metodu pek çok problem tipinde kullanılabilmektedir. BAHS yöntemi kendi içerisinde Genişletilmiş (Chang'in) Analiz Yöntemi(1996), Liou ve Wang'ın Yöntemi (1992), Abdel-Kader ve Yöntemi (2001) gibi farklı çözüm yöntemleri barındırmaktadır. Bu çalışmada Chang (1996) tarafından önerilen Genişletilmiş Analiz Yöntemi kullanılmıştır. Chang'in yaklaşımına göre ikili karşılaştırmalar üçgensel bulanık sayılarla temsil edilmektedir. Bulanık sayıların kullanılması ile tahminden kaynaklanan dezavantajlar giderilmeye çalışılmışır. Chang'in yöntemine göre, her bir ölçüt alınır ve her bir hedef için mertebe analizi uygulanır. Böylece her bir ölçüt için $m$ tane mertebe analiz değerleri elde edilmektedir. $X=\left\{x_{-} 1, x_{-}(2, \ldots) x \_n\right\}$ ölçütler kümesi ve $U=\left\{u_{-} 1, u_{-}(2, \ldots) u_{-} n\right\}$ hedef kümesi olmak üzere, her bir hedef için her ölçüt dikkate alınarak derece analizi (g_i) uygulanır (Denizhan, vd., 2017:66-68). Hedeflere ilişkin m derece analiz değerleri şu şekilde gösterilmektedir;

$\mathrm{M}_{\mathrm{gi}}^{1}, \mathrm{M}_{\mathrm{gi}}^{2}, \ldots ., \mathrm{M}_{\mathrm{gi}}^{\mathrm{m}} \mathrm{i}=1,2, \ldots, \mathrm{n}$

$M_{g i}^{j}(j=1,2, \ldots . n)$

Burada verilen tüm tüm $\mathrm{M}_{\mathrm{gi}}^{\mathrm{m}}$ parametreleri l, $\mathrm{m}$, u olarak ifade edilen üçgensel sayıları göstermektedir. Chang' in mertebe analizi adımları şu şekildedir;

Adım 1: i ölçütüne ilişkin bulanık sentetik derece değeri;

$\mathrm{S}_{\mathrm{i}}=\sum_{\mathrm{j}=1}^{\mathrm{m}} \mathrm{M}_{\mathrm{gi}}^{\mathrm{j}} \otimes\left[\sum_{\mathrm{i}=1}^{\mathrm{n}} \sum_{\mathrm{j}=1}^{\mathrm{m}} \mathrm{M}_{\mathrm{gi}}^{\mathrm{j}}\right]^{-1}$

olarak tanımlanır. Burada $\left(\mathrm{l}_{\mathrm{i}}, \mathrm{m}_{\mathrm{i}}, \mathrm{u}_{\mathrm{i}}\right)$ üçgensel bir bulanık sayı olmak üzere,

$S_{i}=i$. amacın sentez değeri $M_{g i}^{j}=$ her amaca yönelik genişletilmiş değerdir. Burada ifade edilen $\sum_{j=1}^{m} M_{g i}^{j}$ değerini elde etmek için $m$ boyut analiz değerine aşağıda görüldüğü gibi bulanık toplama işlemi uygulanır;

$\sum_{j=1}^{m} M_{g i}^{j}=\left[\sum_{j=1}^{m} l_{j}, \sum_{j=1}^{m} m_{j}, \sum_{j=1}^{m} u_{j}\right]$

$\sum_{i=1}^{n} \sum_{j=1}^{m} M_{g i}^{j}=\left[\sum_{i=1}^{n} l_{i}, \sum_{i=1}^{n} m_{i}, \sum_{i=1}^{n} u_{i}\right]$

Birinci adımın sonunda yukarıdaki vektörün tersi şu şekilde hesaplanmaktadır;

$$
\left[\sum_{\mathrm{i}=1}^{\mathrm{n}} \sum_{\mathrm{j}=1}^{\mathrm{m}} \mathrm{M}_{\mathrm{gi}}^{\mathrm{j}}\right]^{-1}=\left[\frac{1}{\sum_{\mathrm{i}=1}^{\mathrm{n}} \mathrm{u}_{\mathrm{i}}}, \frac{1}{\sum_{\mathrm{i}=1}^{\mathrm{n}} \mathrm{m}_{\mathrm{i}}}, \frac{1}{\sum_{\mathrm{i}=1}^{\mathrm{n}} \mathrm{l}_{\mathrm{i}}}\right]
$$

Adım 2: $\mathrm{M}_{2}=\left(\mathrm{l}_{2}, \mathrm{~m}_{2}, \mathrm{u}_{2}\right) \geq \mathrm{M}_{1}=\left(\mathrm{l}_{1}, \mathrm{~m}_{1}, \mathrm{u}_{1}\right)$ ifadesinin olabilirlik derecesi söyle tanımlanır:

$\mathrm{V}\left(\mathrm{M}_{2} \geq \mathrm{M}_{1}\right)=\sup _{\mathrm{y} \geq \mathrm{x}}=\left[\min \mu_{\mathrm{M} 1}(\mathrm{x}), \mu_{\mathrm{M} 2}(\mathrm{y})\right]$ 
Aşağıdaki şekilde de açıklamak mümkündür:

$V\left(M_{2} \geq M_{1}\right)=\operatorname{hgt}\left(M_{2} \cap M_{1}\right)=\mu_{M 2}(d)= \begin{cases}1 & , m_{2} \geq m_{1} \\ 0 & , l_{1} \geq u_{2}\end{cases}$

Burada karşılaştırılan iki durum için kesişim noktası bulunur. $M_{1}$ ve $M_{2}{ }^{\prime}$ yi kıyaslayabilmek için $V\left(M_{2} \geq M_{1}\right)$ ve $V\left(M_{1} \geq M_{2}\right)$ değerlerinin her ikisi de gerekmektedir.

Adım 3: Konveks bir bulanık sayının $\mathrm{M}_{\mathrm{i}}(\mathrm{i}=1,2,3, \ldots \mathrm{k})$ olmak üzere $\mathrm{k}$ tane konveks sayıdan büyük olmasının olabilirlik derecesi şu şekilde gösterilmektedir;

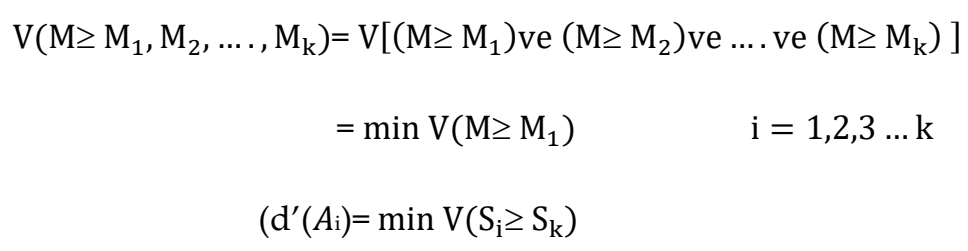

$\mathrm{Bu}$ işlemlerde sırasıyla; 1 . satır diğer tüm satırlarla karşılaştırılır. Bu karşılaştırmalar sonucunda çıkan değerlerin minimumu alınır $\left(\mathrm{d}^{\prime}\left(A_{1}\right)\right)$. Aynı şekilde 2. satırda diğer tüm satırlarla karşılaştırılır ve minimumu alınır $\left(\mathrm{d}^{\prime}\left(\mathrm{A}_{2}\right)\right)$. Bu işlem tüm satırlar için devam ettirilir. Her satır için bulunan minimum değerler birleştirilerek ağırlık vektörü elde edilir.

$W^{\prime}=\left(d^{\prime}\left(A_{1}\right), d^{\prime}\left(A_{2}\right), \ldots \ldots, d^{\prime}\left(A_{N}\right)\right)^{T}$

Adım 4: Ağırlık vektörü normalize edilir. Burada W, bulanık olmayan bir sayıdır. normalize edilmiş ağırlık vektörü aşağıdaki gibi ifade edilmektedir (Denizhan, vd., 2017:66-68; Acer, 2009;Aydın, 2008;93).

$W=\left(d\left(A_{1}\right), d\left(A_{2}\right), \ldots \ldots, d\left(A_{N}\right)\right)^{T}$

Çalışmamızda, konteyner terminallerinde kullanımı yaygın olmayan RFID teknolojisi sisteminin seçimi gibi karar verme süreci karmaşık, belirsizlikler ve reel uygulamalara ait verilere ulaşma zorluğu içeren bir problemin çözümü için en uygun metot olan BAHS metodu kullanılmıştır. Bu metot sübjektif değerlendirmeleri belirli matematiksel sınırlar içine alarak daha gerçekçi bir çözüm sunup ortaya daha somut alternatifler çıkarmaktadır.

\subsection{Veriseti ve Verilerin Analizi}

Pek çok iş sahasında olduğu gibi konteyner terminallerinde de RFID teknolojisinin kullanım alanları ve beklentiler çok çeşitlidir. Bu bağlamda bu teknolojiye yatırım yapma kararı alan terminaller için ihtiyaçlarına yönelik sistem alternatiflerini analiz edip en doğru alternatifi belirlemeleri büyük önem taşımaktadır. Bu amaçla belirlenen kriterler ile oluşturulan model, literatüre ciddi bir katkı sağlayacaktır. Diğer sektörlerde RFID uygulama seçimi hakkında pek çok çalışma ve kriter bulunmaktadır. Belirlenen bu kriterler, RFID teknolojisini incelemiş ve bu teknolojiyi bilen üç konteyner limanımızda, RFID teknolojisi ile direkt alakalı departmanlarda karar verici olarak görev alan 24 uzman ile yapılan yüz yüze mülakatlarla analiz edilmiş ve çalışmamızda kullanımı uygun olanlar belirlenmiştir. Ayrıca yapılan mülakatlarda eklenebileceği düşünülen kriterler de modele eklenmiştir. Çalışmamıza katılan uzmanlar; 
liman işletme (9 kişi), operasyon (8 kişi) ve IT (7 kişi) departmanlarında yetkili kişilerden oluşmaktadır. Belirlenen ana ve alt kriterler Tablo 2' de belirtilmiştir.

Tablo 2. Konteyner Terminallerine En Uygun RFID Uygulamasının Seçiminde Kullanılacak Ana ve Alt Kriterler

\begin{tabular}{|c|c|c|}
\hline Ana Kriterler & Alt Kriterler & Referanslar \\
\hline Maliyet (M) & $\begin{array}{l}\text { Donanım Maliyeti (M1), Yazılım Maliyeti (M2), } \\
\text { Entegrasyon Maliyeti (M3), Eğitim Maliyeti (M4), } \\
\text { Bakım Maliyeti (M5), Süreç Yenileme Maliyeti } \\
\text { (M6) }\end{array}$ & $\begin{array}{l}\text { Crum vd. (1996); Smith ve Konsynski (2003); } \\
\text { Upfold ve Liu (2010); Oranlı, (2007); Lin, (2009); } \\
\text { uzman görüşleri. }\end{array}$ \\
\hline Beklenen Fayda (BF) & $\begin{array}{l}\text { Artan Liman Güvenliği (BF1), Artan Yük Güvenliği } \\
\text { (BF2), Artan Operasyonel Verimlilik (BF3), Artan } \\
\text { Prestij (BF4) }\end{array}$ & $\begin{array}{l}\text { Perera vd. (2003); Perera vd. (2003); uzman } \\
\text { görüşleri. }\end{array}$ \\
\hline $\begin{array}{l}\text { Teknik Risk Unsurları } \\
\text { (TRU) }\end{array}$ & $\begin{array}{lcl}\text { Güvenlik } & \text { (TRU1), Sağlı̆ga Etki } & \text { (TRU2), } \\
\text { Karmaşıklık } \quad \text { (Kullanım Kolaylığı) } & \text { (TRU3), } \\
\text { Güvenilirlik Ve Performans (TRU4) } & \end{array}$ & $\begin{array}{l}\text { Chong ve Chan (2012); Lin, (2009); Rogers } \\
\text { (2003); Schmitt ve Michahelles (2009); uzman } \\
\text { görüşleri. }\end{array}$ \\
\hline Çevresel Koşular (ÇK) & $\begin{array}{l}\begin{array}{l}\text { Paydaşlarla İşbirliği Seviyesi (ÇK1), } \\
\text { Uyumluluk }\end{array} \text { (ÇK2), Tedarikçi Seviörel } \\
\text { Ulusal Ve }\end{array}$ & $\begin{array}{l}\text { Tornatzky ve Fleischer (1990); Seymour vd. } \\
\text { (2007); Li vd. (2010); Whitaker vd. (2007); Wang } \\
\text { vd. (2010); Wang vd. (2010); Anand ve } \\
\text { Kulshreshtha (2007); Schmitt vd. (2007); } \\
\text { Chewelos vd. (2001); Van Heck ve Ribbers } \\
\text { (1999); uzman görüşleri. }\end{array}$ \\
\hline $\begin{array}{l}\text { Örgütsel } \\
(\text { ÖK) }\end{array}$ & $\begin{array}{l}\text { Liman Sistemleriyle Uyumluluk (ÖK1), Üst } \\
\text { Yönetim Desteği (ÖK2), Finansal Hazır Olma } \\
\text { (ÖK3), Finansal Olmayan Hazır Olma (ÖK4), } \\
\text { Çalışanların Direnci (ÖK5) }\end{array}$ & $\begin{array}{l}\text { Öztürk (2010); Wang vd. (2010); Sharma ve } \\
\text { Citurs (2005); Ngai vd. (2007); Schmitt vd. } \\
\text { (2007); Iacovou vd. (1995); Lee ve Shim (2007); } \\
\text { uzman görüşleri. }\end{array}$ \\
\hline
\end{tabular}

Akademik literatür ve uzman görüşleri doğrultusunda Tablo 2' de belirtilen 5 ana ve 25 alt kriter belirlenmiştir. Tüm ana, alt kriter ve alternatifler için gösterim kolaylığı olması açısından kısaltma kullanılacaktır. İlgili kısaltmalar parantez içinde gösterilmiştir.

Maliyet (M) Ana Kriteri: Crum vd. (1996)'ya göre yeni bir teknolojinin maliyeti; “gerekli yazılım ve donanım altyapısı ve iş ortakları arasındaki elektronik bağlantıların kurulmasına yönelik masraflar" olarak tanımlanmaktadır. Smith ve Konsynski (2003) çalışmasında RFID ile bağlantılı altı maliyet türü tanımlanmıştır. Bunlar; donanım, yazılım, entegrasyon, eğitim, bakım ve süreç yenileme maliyetleridir. Upfold ve Liu (2010)'a göre maliyet RFID adaptasyonlarında en kilit faktörlerden biridir. Donanım, yazılım ve etiketlerin maliyetlerinden oluşan yüksek kurulum maliyetleri karar vericileri yatırımın geri dönüşü hususunda endişelendirmektedir. Buna ek olarak belirtilmelidir ki; RFID yatırımları mevcut şartlarda yüksek olsa bile yapılmakta olan AR-GE çalışmaları ile her geçen gün maliyetler aşağıya çekilmektedir. Maliyet ana kriterine bağlı 6 alt kriter aşağıdaki gibidir;

Donanım Maliyeti (M1): Sistemin kurulumunda satın alınan etiketler, okuyucular, antenler, bilgisayarlar ve ağ ekipmanlarına ait maliyetlerden oluşmaktadır. Yazılım Maliyeti (M2): Mevcut liman sistemlerinden bağımsız, sadece kurulacak RFID sistemine özgü olan yazılımlara ait maliyetlerden oluşmaktadır. Entegrasyon Maliyeti (M3): Firmada mevcutta çalışan uygulamalar ve kullanılan programlar ile yeni kurulacak olan sistemin entegrasyonu sağlanmalıdır. Bu, sistemin başarılı olabilmesi için en önemli aşamalardan birisidir. Çünkü kurulacak sistem bağımsız olarak çalışır ve yapı içerisindeki diğer kısımlarla bütünlük sağlanmaz ise sistemin ne derecede başarılı olduğu ve etkinlik yarattı̆̆ anlaşılamayacaktır (Oranlı, 2007). Eğitim Maliyeti (M4):Limana kurulacak yeni teknoloji ile liman çalışanlarının yenilenen süreçlere ve ekipman kullanımına yönelik olarak eğitilmesi sonucu oluşacak maliyetleri kapsamaktadır. Bakım Maliyeti (M5): Sistem sağlayıcılar tarafından, kurulum sırasında yapılan sözleşmede belirtilen periyotlarda sistemin kontrol edilmesi ve herhangi bir sorunla karşılaşıldığında teknik destek alınması gerekmektedir (Oranlı, 2007). Süreç Yenileme Maliyeti (M6):Liman gelecekte doğabilecek ihtiyaç ve talepler doğrultusunda adaptasyonunu yaptığı sistemi yenilemek zorunda kalabilmektedir. Bu bağlamda yeni maliyetler doğabilecektir (Lin, 2009:1-7).

Beklenen Fayda (BF) Ana Kriteri: Perera vd. (2003) çalışmasında göreli avantajı, bir yeniliğin, yerine geçtiği fikirden veya mevcut durumdan ne kadar daha fazla örgütsel fayda sağladığı yönündeki algının derecesi olarak tanımlamaktadır. Matta ve Moberg (2006)'ya göre göreli avantaj ve rekabet, teknoloji adaptasyonuna 


\section{S. Alnıpak- G. Bilen Alkan 13/4 (2021) 3889-3909}

yönelik değişkenlerin en önemlileridir. En temel ifadesi ile bağıl avantaj, bir kuruluşun ilgili teknolojiden beklediği faydalardır. Kuruluşların yenilikleri uygulayarak kazanabilecekleri avantajları değerlendirmeleri tüm sektörler için üzerinde durulması gereken bir konudur. Konteyner terminallerinde RFID uygulamalarına bağlı olarak 4 temel fayda beklenmektedir. Bunlar; Artan Liman Güvenliği (BF1): Etiketlerin ilgili obje ve/veya objelere takılması sonucunda; objenin otomatik olarak tanınması ve takibi sağlanabilmektedir. Objelerin; ne veya kim olduğu, nereden ve ne zaman geçtiği belirlenebilecek ve limanın güvenliği artacaktır. Artan Yük Güvenliği (BF2): Özellikle konteynere takılacak e-mühürler vasıtasıyla sağlanabilecektir. Bunun yanı sıra emühür kullanılmadan da araca, şoföre ve/veya konteynerlere uygulanacak etiketlendirme işlemleri ile doğru yükün doğru araç ve sürücü ile taşınması ve doğru ekipmana doğru yükün yüklenmesi gibi yük güvenliğini arttıran çözümler mümkün olabilmektedir. Artan Operasyonel Verimlilik (BF3): RFID uygulamaları, takip ve izleme kolaylığı ve süreç otomatizasyonunda sağladığı artışa bağlı olarak terminallerin operasyonel verimliliklerinde yükselme sağlayabilmektedir. Bunun için liman içi ekipmanların ve/veya liman dışı öğelerin etiketlendirilmesi gerekmektedir. Artan Prestij (BF4): Limanların en son teknoloji ürünü sistemlere sahip olması müşteriye karşı bir prestij ve gösteriş niteliği taşımaktadır.

Teknik Risk Unsurları (TRU) Ana Kriteri: Her teknolojinin uygulanmasında kendi karakteristiğinden doğan bazı teknik riskler bulunmaktadır. Teknoloji uygulamalarında teknik risk daha çok bilgi güvenliği riski olarak algılanmakla beraber RFID için bu riskler çok çeşitli olabilmektedir. Bu kritere bağlı olarak 4 temel alt kriter belirlenmiştir. Bunlar; Güvenlik (TRU1): RFID adaptasyonun sürecinin ilk aşamalarında, bu teknolojiye aşina olmayan ve tecrübeleri kısıtlı olan firmalarda, güvenliğe ve gizliliğe yönelik olarak büyük şüpheler oluşabilmektedir. Chong ve Chan (2012)'ye göre güvenlik problemi, firmaların kablosuz ve mobil teknolojilere karşı duyduğu en büyük endişelerden birisidir. Çünkü etiketlerin üzerinde depolanan veriler kablosuz olarak yayımlanmaktadır. Bu verilerin hackerlar tarafından gizlice elde edilme riski vardır. Sağlığa Etki (TRU2): RFID teknolojisinin kullanımında radyo frekansının insan sağlığına olan etkileri en çok tartışılan hususların başında gelmektedir. Sistemde kullanılacak ekipmanlar, kullanım frekansları ve kullanım yoğunluğu tüm çalışanlar için tehdit unsuru olabilmektedir (Lin, 2009: 1-7). Karmaşıklık (Kullanım Kolaylı̆̆ı) (TRU3): Rogers (2003)'e göre karmaşıklık, "bir yeniliğin anlaşılması ve kullanılmasının diğerlerine göre ne derece zor olduğu" olarak tanımlanmaktadır. Schmitt ve Michahelles (2009) çalışmasına göre; yüksek karmaşıklık içeren yenilikler örgüt içinde yüksek miktarda şüpheyi de beraberinde getirmektedir. Her RFID teknolojisi uygulamasının kendine has özellikleri bulunmaktadır. Her bir alternatif teknik olarak farklı karmaşıklıkları barındırmaktadır. Bu bağlamda seçilecek alternatifin kullanıcı dostu özelliklere sahip olması ve gelecekte kolayca geliştirilebilir özellikleri barındırması önemlidir. Güvenilirlik ve Performans (TRU4): Her RFID uygulaması için etiketlerin okunma oranı, hızı, elde edilecek verilerin doğruluğu, aynı anda okunan etiket sayıları, okuyucuların okuma menzilleri, verilerin güncellenebilmesi, insan gücü gereksinimi vb. parametreler farklılık arz etmektedir.

Çevresel Koşullar (ÇK) Ana Kriteri: Tornatzky ve Fleischer (1990)'a göre çevresel içerik "bir firmanın faaliyetlerini yürüttüğü sektör, rakipleri, tedarik edilen kaynaklara erişimi ve devlet kurumları ile ilişkileri" olarak tanımlanmıştır. Çevresel koşullar aşağıdaki gibi belirlenmiştir. Bunlar; Paydaşlarla İşbirliği Seviyesi (ÇK1): Seymour vd. (2007) 'e göre konteyner taşımacıllğında sektörün kendine has yapısı RFID adaptasyonunda önem arz etmektedir. Bu sürecin liman dışındaki aktörlerinin (özellikle limanın en sık işbirliği içinde olduğu acente ve taşıyıcı firmalar) limanın ilgili yatırımına yönelik işbirlikçi ve gönüllü (maliyet paylaşımı, RFID'e yönelik re-organizasyon vb) olmaları önemlidir. Sektörel Uygunluk (ÇK2): RFID uygulamaları kullanılacağı sektörün doğasına mümkün olduğunca uygun olmalıdır. Limanlar her ne kadar uygulamayı genellikle lokal olarak gerçekleştirse de sektörün diğer aktörleri ve mevcut iş süreçleri bu uygulamadan etkilenecek ve sistemler arasında uyumsuzluklar baş gösterebilecektir. Bu bağlamda seçilecek alternatifin uygulanabilirliği dikkatle analiz edilmelidir. Tedarikçi Seviyesi (ÇK3): Li vd. (2010) ‘a göre RFID uygulamaları bazı sektörlerde yeni yeni gelişmektedir ve henüz yeterli miktarda firma tarafından uzmanlaşma sağlanamamıştır. Bu sebeple tedarikçilerin bilgi ve destek seviyeleri firmalar için önemlidir. Whitaker vd. (2007) 'e göre firmaların başarılı RFID uygulamaları için uzman tedarikçilerin varlığ kaçınılmazdır. Ulusal ve Uluslararası Kanuni Baskı (ÇK4): Wang vd. (2010) ‘a göre dış baskı; bir teknolojinin adaptasyonu kararına yönelik olarak ticari ortakların, müşterilerin ve devlet tarafından firma üzerinde oluşturulan baskının yoğunluk derecesini yansıtmaktadır. Anand ve Kulshreshtha (2007)'e göre firmalar açısından çevresel faktörlerden biri olan devletin yaptığı kanuni düzenlemelerin bir teknolojinin 


\section{S. Alnıpak- G. Bilen Alkan 13/4 (2021) 3889-3909}

adaptasyonunda büyük etkisi vardır. İthalat ve ihracat yapılan pek çok ülke, güvenlik ve tedarik zincirinin izlenebilirliği ihtiyaçları doğrultusunda RFID teknolojisinin kullanımını talep edebilmektedir.

Standardizasyon (ÇK5): RFID teknolojisi yaygınlaşmaya devam ettikçe küresel standartlar oluşturulmasına duyulan ihtiyaç ta artmaktadır. Schmitt vd. (2007)'ye göre; etkin RFID kullanımı için tamamen küreselleşmiş bir iş ortamı ve örgütlerin bilgi ve iletişim teknolojilerinin birlikte çalışabilirlik (interoperability) seviyelerinin yüksek olması temel gerekliliklerdir. Bu bağlamda, RFID standartları (RF protokolü, etiket üzeri verilerin formatı vb.) - endüstriler için çözülmesi gereken konulardandır. Narsoo ve Sunhaloo (2009)'a göre RFID teknolojisinin karşı karşıya bulunduğu zorluklardan ikisi; teknoloji spesifikasyonu ve uygulama için bazı standartlardaki eksikliklerdir. Global olarak standartların oluşturulması ve kabul görmesi RFID uygulamasına olumlu etkilerde bulunacaktır. Rekabet Baskısı (ÇK6): Chewelos vd. (2001) 'e göre rekabet; ilgili endüstrideki rakipleriniz ile baş edebilme yeteneği olarak tanımlanmaktadır. Wang vd. (2010) ‘a göre rekabet, yeni teknoloji adaptasyonunun önemli bir belirleyicisidir. Van Heck ve Ribbers (1999) çalışmasına göre pazar rekabeti arttıkça, firmalar yenilikler aracılığıyla rekabet açısından avantaj elde etmenin yollarını aramaktadır.

Örgütsel Koşullar (ÖK) Ana Kriteri: Öztürk (2010)'a göre örgütsel içeriği; firma büyüklüğü ve kapsamı, yönetimsel yapının merkezileşmesi, resmileşmesi ve karmaşıklığı; insan kaynaklarının kalitesi ve kuruluş içinde yer alan kaynakların miktarı vb. oluşturmaktadır. Kuruluş yapısı ve süreçleri, uygulama alternatifinin seçimini sınırlayabilmekte veya kolaylaştırabilmektedir. Bu nedenle örgütsel koşulların uygulama seçimi kararı üzerindeki etkilerini göz önünde bulundurmak gerekmektedir. ÖK ana kriteri bazında limanlarda RFID uygulama seçim kararı belirleyicileri olarak aşağıdaki alt kriterler belirlenmiştir.

Liman Sistemleriyle Uyumluluk (ÖK1): Wang vd. (2010) 'a göre uyumluluk; bir yeniliğin, potansiyel uygulamacılarının ihtiyaçları veya mevcut uygulamalarıyla (halen kullandığı IT altyapısı, iş süreçleri vb) ne kadar uyumlu olarak algılandığını tanımlamaktadır. Uyumluluk derecesinin yüksek olması yeniliğin uygulanmasını hızlandıran bir faktör olarak tanımlanmıştır. Sharma ve Citurs (2005) çalışmasında "Uyumluluk" parametresinin RFID uygulaması seçimlerini önemli derecede etkilediğini belirtmiştir. Ayrıca Ngai vd. (2007)'e göre örgütün mevcut sistem ve stratejileri ile RFID uygulama alternatifinin uyumluluk göstermesi adaptasyon kararını direkt etkilemektedir. Üst Yönetim Desteği (ÖK2): Wang vd. (2010) 'a göre yeni uygulamaların seçiminde üst yönetim desteği önemli bir faktördür ve adaptasyonla pozitif ilişkisi olduğu saptanmıştır. Schmitt vd. (2007)'ye göre üst yönetim desteği RFID uygulaması seçimi kararında kilit bir rol oynamaktadır. Üst yönetim, yenilik için vizyon, destek ve olumlu bir ortam yaratma isteği sağlayabilmektedir. Finansal Hazır Olma (ÖK3): Iacovou vd. (1995) ‘e göre örgütsel düzeyde hazır olma durumu kuruluşun (1) finansal, (2) teknolojik kaynaklarının düzeyiyle ilgilidir. Finansal kaynaklar yeni bir teknolojik yeniliğin maliyeti, sonraki iyileştirme maliyetleri ve kullanım sırasında devam eden bakım ve onarım giderlerini ödemek için mevcut olan finansal kaynakları ifade etmektefir. Finansal Olmayan Hazır Olma (ÖK4): Finansal olmayan hazır olmayı ifade eden kaynaklar limandaki bilgi teknolojileri, diğer çalışanların yeterliliği ve bilgi düzeyi ile ilgilidir. Öztürk (2010)'a göre bu kriter; bir kuruluşta RFID teknolojisi hakkında bilinenleri ifade etmektedir. Lee ve Shim (2007) çalışmasında örgütsel olarak hazır olma derecesinin artması ile seçilecek uygulamalarda büyük değişiklikler olabileceğini ortaya koymuştur. Çalışanların Direnci (ÖK5): Birey ve grupların mevcut olduğu yerde denge durumunu bozan çoğu değişiklik problem yaratabilmektedir. Seçilecek RFID uygulamasının getireceği değişim ve yeniliklere liman çalışanları direnç gösterebilmektedir.

RFID teknolojisi konteyner terminallerinin pek çok alanında kullanılabilmektedir. Bu uygulamalar etiketlendirilen objelere ve okuyucuların konuldukları bölgelere göre farklı amaçları içermektedir. Alternatifler belirlenirken gerek tekil gerek ise de hibrit kullanımlar düşünülmüş ve dünyanın önde gelen konteyner terminallerindeki uygulama alternatifleri de göz önünde tutulmuştur. Tüm objelerin aktif etiket ile etiketlendirilmesi ve buna uygun olan okuyucuların kullanılması düşünülmüştür. Seçimi yapılacak alternatifler Tablo 3'te gösterilmiştir. 
S. Alnıpak- G. Bilen Alkan 13/4 (2021) 3889-3909

Tablo 3. Türk Konteyner Terminallerine En Uygun RFID Uygulamasının Seçiminde Analiz Edilecek Alternatifler

\begin{tabular}{|c|l|l|}
\hline Alternatif & \multicolumn{1}{|c|}{ Okuyucu Lokasyonu } & \multicolumn{1}{|c|}{ Etiketlenen Obje } \\
\hline A1 & Giriş/Çıkış Kapıları & Taşıyıcı Araç (Aktif Etiketli) \\
\hline A2 & Giriş/Çıkış Kapıları & $\begin{array}{l}\text { Konteyner (Gövdeye Aktif etiketli) + Taşıyıcı Araç (Aktif } \\
\text { Etiketli) }\end{array}$ \\
\hline A3 & Giriş/Çıkış Kapıları & $\begin{array}{l}\text { Konteyner (Kapısına Aktif etiketli E-Mühür) + Taşıyıcı Araç } \\
\text { (Aktif Etiketli) }\end{array}$ \\
\hline A4 & $\begin{array}{l}\text { Giriş/Çıkış Kapıları + Terminal İç } \\
\text { Bölge }\end{array}$ & $\begin{array}{l}\text { Konteyner (Gövdeye Aktif etiketli) + Taşıyıcı Araç (Aktif } \\
\text { Etiketli)+ Liman Ekipmanları (Aktif Etiketli) }\end{array}$ \\
\hline A5 & $\begin{array}{l}\text { Giriş/Çıkış Kapıları + Terminal İç } \\
\text { Bölge }\end{array}$ & $\begin{array}{l}\text { Konteyner (Kapısına Aktif etiketli E-Mühür) + Taşıyıcı Araç } \\
\text { (Aktif Etiketli) + Liman Ekipmanları (Aktif Etiketli) }\end{array}$ \\
\hline
\end{tabular}

\section{Bulgular}

24 uzmana uygulanan anketten elde edilen veriler Chang'ın Mertebe Analizi Tekniği aşamaları uygulanarak analiz edilmiş ve aşağıdaki bulgulara ulaşılmıştır. Problemin çözümünde kullanılan bulanık karşılaştırma dereceleri Tablo 4'te gösterilmiştir.

Tablo 4. Kriter Bulanık Karşılaştırma Dereceleri

\begin{tabular}{|lcc|}
\hline \multicolumn{1}{|c|}{ Dilsel Ölçek } & Üçgensel Bulanık Ölçek & Üçgensel Karşıt Bulanık Ölçek \\
\hline Eşit & $(1,1,1)$ & $(1,1,1)$ \\
Eşite Yakın Daha Önemli & $(1 / 2,1,3 / 2)$ & $(2 / 3,1,2)$ \\
Biraz Daha Önemli & $(1,3 / 2,2)$ & $(1 / 2,2 / 3,1)$ \\
Çok Daha Önemli & $(3 / 2,2,5 / 2)$ & $(2 / 5,1 / 2,2 / 3)$ \\
Pek Çok Daha Önemli & $(2,5 / 2,3)$ & $(1 / 3,2 / 5,1 / 2)$ \\
Tamamen Daha Önemli & $(5 / 2,3,7 / 2)$ & $(2 / 7,1 / 3,2 / 5)$ \\
\hline
\end{tabular}

Öncelikle Tablo 4 yardımıyla ana kriterlerin uzmanlar tarafından yapılan ikili karşılaştırmaları sonucu Tablo 5'te yer alan öncelik matrisi oluşturulur.

Tablo 5. Ana Kriterlerin Öncelik Matrisi

\begin{tabular}{|c|c|c|c|c|c|c|c|c|c|c|c|c|c|c|c|}
\hline & \multicolumn{4}{|c|}{ M } & \multicolumn{4}{|c|}{ BF } & \multicolumn{4}{|c|}{ TRU } & \multicolumn{3}{|c|}{ ÇK } \\
\hline M & $\mathbf{1 , 0 0}$ & $\mathbf{1 , 0 0}$ & $\mathbf{1 , 0 0}$ & 0,79 & 1,21 & 1,75 & $\mathbf{0 , 9 0}$ & $\mathbf{1 , 2 6}$ & $\mathbf{1 , 7 3}$ & 1,36 & 1,75 & 2,19 & $\mathbf{0 , 7 1}$ & $\mathbf{0 , 9 6}$ & $\mathbf{1 , 2 5}$ \\
\hline BF & $\mathbf{0 , 5 7}$ & $\mathbf{0 , 5 7}$ & $\mathbf{0 , 5 7}$ & 1,00 & 1,00 & 1,00 & $\mathbf{0 , 9 0}$ & $\mathbf{1 , 1 3}$ & $\mathbf{1 , 4 1}$ & 0,89 & 1,21 & 1,54 & $\mathbf{0 , 6 7}$ & $\mathbf{1 , 0 1}$ & $\mathbf{1 , 5 3}$ \\
\hline TRU & $\mathbf{0 , 5 8}$ & $\mathbf{0 , 5 8}$ & $\mathbf{0 , 5 8}$ & 0,71 & 0,89 & 1,11 & $\mathbf{1 , 0 0}$ & $\mathbf{1 , 0 0}$ & $\mathbf{1 , 0 0}$ & 0,79 & 1,10 & 1,42 & $\mathbf{0 , 6 3}$ & $\mathbf{0 , 8 7}$ & $\mathbf{1 , 1 2}$ \\
\hline ÇK & $\mathbf{0 , 4 6}$ & $\mathbf{0 , 4 6}$ & $\mathbf{0 , 4 6}$ & 0,65 & 0,83 & 1,12 & $\mathbf{0 , 7 0}$ & $\mathbf{0 , 9 1}$ & $\mathbf{1 , 2 6}$ & 1,00 & 1,00 & 1,00 & $\mathbf{0 , 6 2}$ & $\mathbf{0 , 8 7}$ & $\mathbf{1 , 2 5}$ \\
\hline ÖK & $\mathbf{0 , 8 0}$ & $\mathbf{0 , 8 0}$ & $\mathbf{0 , 8 0}$ & 0,65 & 0,99 & 1,49 & $\mathbf{0 , 8 9}$ & $\mathbf{1 , 1 5}$ & $\mathbf{1 , 5 8}$ & 0,80 & 1,14 & 1,60 & $\mathbf{1 , 0 0}$ & $\mathbf{1 , 0 0}$ & $\mathbf{1 , 0 0}$ \\
\hline
\end{tabular}

Öncelik matrisine göre ana kriterlerin ağırlıklarını belirleyebilmek için bulanık sentetik mertebenin değerleri hesaplanır.

$\mathrm{SM}=(4,76,6,17,7,92) *(0,0304,0,0392,0,0498)=(0,14,0,24,0,39)$

$\operatorname{SBF}=(4,03,5,17,6,75) *(0,03040,03920,0498)=(0,120,200,34)$

STRU $=(3,71,4,65,5,77) *(0,03040,03920,0498)=(0,110,180,29)$

$\mathrm{SÇK}=(3,43,4,19,5,37) *(0,03040,03920,0498)=(0,100,160,27)$

SÖK $=(4,15,5,33,7,08) *(0,03040,03920,0498)=(0,130,210,35)$

Bir sonraki aşamada olabilirlik değerleri hesaplanır. Olabilirlik değerleri Tablo 6 'da verilmiştir. 
S. Alnıpak- G. Bilen Alkan 13/4 (2021) 3889-3909

Tablo 6. Ana kriterlerin Olabilirlik Değerleri

\begin{tabular}{|c|c|c|c|c|c|c|c|c|c|c|c|c|c|c|c|}
\hline $\mathbf{V}$ & $\mathrm{S}_{\mathrm{M}}>=$ & DI & 1,00 & $\mathbf{V}$ & $\mathrm{S}_{\mathrm{M}}>=$ & TRU & 1,00 & $\mathbf{V}$ & $\mathrm{S}_{\mathrm{M}}>=$ & $\mathrm{S}_{C \zeta \mathrm{K}}$ & 1,00 & $\mathbf{V}$ & $\mathrm{S}_{\mathrm{M}}>=$ & $\mathrm{S}_{\text {ÖK }}$ & 1,00 \\
\hline$=$ & $\mathrm{S}_{\mathrm{BF}}>=$ & & 00 & $\mathbf{V}$ & $\mathrm{S}_{\mathrm{BF}}>=$ & & 1,00 & $\mathbf{V}$ & & $\mathrm{S}_{\text {ÖK }}$ & 97 & $\mathbf{V}$ & $\mathrm{S}_{\mathrm{BF}}>=$ & $\mathrm{S}_{\mathrm{M}}$ & 83 \\
\hline $\mathbf{V}$ & $\mathrm{S}_{\mathrm{TRU}}>=$ & & 1,00 & $\mathbf{V}$ & & & 6 & $\mathbf{V}$ & & & 71 & $\mathbf{V}$ & & & 8 \\
\hline $\mathbf{V}$ & $\mathrm{S}_{C_{\mathrm{C}}>=}$ & - & 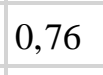 & $\mathbf{V}$ & & & & $\mathbf{V}$ & & & 0,79 & $\mathbf{V}$ & & $S_{\text {TRU }}$ & 89 \\
\hline 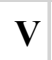 & $\mathrm{S}_{\mathrm{ÖK}}>=$ & $\mathrm{S}_{\mathrm{M}}$ & 0,86 & $\mathbf{V}$ & $\mathrm{S}_{\mathrm{OKK}}>=$ & $\mathrm{S}_{\mathrm{BF}}$ & 1,00 & $\mathbf{V}$ & $\mathrm{S}_{\mathrm{ÖK}}>=$ & $\mathrm{S}_{\mathrm{TRU}}$ & 1,00 & $\mathbf{V}$ & $S_{\ddot{O} K}>=$ & $\mathrm{S}_{\mathrm{CCK}}$ & 1,00 \\
\hline
\end{tabular}

Her satır için bulunan minimum değerler birleştirilerek ağırlık vektörü elde edilir. Min D değerlerinin hesaplanmasıly bulunan $W^{\prime}(1.00,0.83,0.71,0.61,0.86) T$ ağırlıklar vektörünün normalizasyonu sonucu $\mathrm{W}=(0.25,0.21,0.18,0.15,0.22) \mathrm{T}$ olarak hesaplanmıştır.Ana kriterlerin ağırlıkları belirlendikten sonra alt kriterlerin öncelik matrisleri oluşturulur. Oluşturulan matrisler yardımıyla yukarıda yapılan işlemlerin aynıları bu matrislere de uygulanarak alt kriterlerin ağırlıkları belirlenir ve çözüme devam edilir. Tablo $7,8,9,10$ ve 11 'de özet olarak alt kriterlerin karşılaştırılması, önem ağırlıkları ve ilgili kriterlerin her bir alternatife göre değerlendirilmesi belirtilmiştir.

Tablo 7. Maliyet Alt Kriterlerinin Ağırlıkları Ve Alternatiflere Göre Değerlendirilmesi

\begin{tabular}{|c|c|c|c|c|c|c|c|}
\hline \multirow{2}{*}{ ĂğIrlıklar (w) } & $\mathbf{0 . 3 1}$ & $\mathbf{0 . 2 2}$ & $\mathbf{0 . 1 0}$ & $\mathbf{0 . 0 1}$ & $\mathbf{0 . 1 5}$ & $\mathbf{0 . 2 1}$ & \multirow{2}{*}{$\begin{array}{c}\text { SONUÇ } \\
\text { SKORU }\end{array}$} \\
\cline { 2 - 7 } & $\mathrm{M} 1$ & $\mathrm{M} 2$ & $\mathrm{M} 3$ & $\mathrm{M} 4$ & $\mathrm{M} 5$ & $\mathrm{M} 6$ & \\
\hline $\mathrm{A}_{1}$ & 0,82 & 0,55 & 0,47 & 0,32 & 0,87 & 0,75 & $\mathbf{0 , 7 1}$ \\
\hline $\mathrm{A}_{2}$ & 0,18 & 0,41 & 0,38 & 0,31 & 0,13 & 0,11 & $\mathbf{0 , 2 3}$ \\
\hline $\mathrm{A}_{3}$ & 0,00 & 0,00 & 0,14 & 0,25 & 0,00 & 0,06 & $\mathbf{0 , 0 3}$ \\
\hline $\mathrm{A}_{4}$ & 0,00 & 0,04 & 0,00 & 0,06 & 0,00 & 0,04 & $\mathbf{0 , 0 2}$ \\
\hline $\mathrm{A}_{5}$ & 0,00 & 0,00 & 0,00 & 0,05 & 0,00 & 0,03 & $\mathbf{0 , 0 1}$ \\
\hline
\end{tabular}

Tablo 8. Beklenen Fayda Alt Kriterlerinin Ağırlıkları Ve Alternatiflere Göre Değerlendirilmesi

\begin{tabular}{|c|c|c|c|c|c|}
\hline \multirow{2}{*}{ Ağırliklar $(w)$} & 0.29 & 0.30 & 0.35 & 0.06 & \multirow{2}{*}{ SONUÇ SKORU } \\
\cline { 2 - 5 } & BF1 & BF2 & BF3 & BF4 & 0,05 \\
\hline $\mathrm{A}_{1}$ & 0,12 & 0,00 & 0,04 & 0,08 & 0,09 \\
\hline $\mathrm{A}_{2}$ & 0,16 & 0,00 & 0,09 & 0,12 & 0,20 \\
\hline $\mathrm{A}_{3}$ & 0,16 & 0,36 & 0,09 & 0,12 & 0,26 \\
\hline $\mathrm{A}_{4}$ & 0,27 & 0,14 & 0,35 & 0,30 & 0,41 \\
\hline $\mathrm{A}_{5}$ & 0,29 & 0,49 & 0,44 & 0,37 & 0 \\
\hline
\end{tabular}

Tablo 9. Teknik Risk Unsurları Alt Kriterlerinin Ağırlıkları Ve Alternatiflere Göre Değerlendirilmesi

\begin{tabular}{|c|c|c|c|c|c|}
\hline \multirow{2}{*}{ Ağırliklar $(\mathrm{w})$} & 0.30 & 0.09 & 0.30 & 0.31 & \multirow{2}{*}{ SONUÇ SKORU } \\
\cline { 2 - 5 } & TRU1 & TRU 2 & TRU 3 & TRU 4 & 0,55 \\
\hline $\mathrm{A}_{1}$ & 0,30 & 0,46 & 0,77 & 0,62 & 0,23 \\
\hline $\mathrm{A}_{2}$ & 0,22 & 0,28 & 0,18 & 0,26 & 0,13 \\
\hline $\mathrm{A}_{3}$ & 0,21 & 0,24 & 0,02 & 0,12 & 0,06 \\
\hline $\mathrm{A}_{4}$ & 0,16 & 0,01 & 0,03 & 0,00 & 0,03 \\
\hline $\mathrm{A}_{5}$ & 0,11 & 0,01 & 0,00 & 0,00 & \\
\hline
\end{tabular}


S. Alnıpak- G. Bilen Alkan 13/4 (2021) 3889-3909

Tablo 10. Çevresel Koşullar Alt Kriterlerinin Ağırlıkları Ve Alternatiflere Göre Değerlendirilmesi

\begin{tabular}{|c|c|c|c|c|c|c|c|}
\hline \multirow{2}{*}{ Ağırlıklar $(w)$} & 0.21 & 0.24 & 0.06 & 0.23 & 0.21 & 0.05 & $\begin{array}{c}\text { SONUÇ } \\
\text { SKORU }\end{array}$ \\
\cline { 2 - 8 } & ÇK1 & ÇK2 & ÇK3 & ÇK4 & ÇK5 & ÇK6 & 0,43 \\
\hline $\mathrm{A}_{1}$ & 0,70 & 0,37 & 0,41 & 0,35 & 0,40 & 0,11 & 0,28 \\
\hline $\mathrm{A}_{2}$ & 0,18 & 0,33 & 0,35 & 0,27 & 0,35 & 0,16 & 0,10 \\
\hline $\mathrm{A}_{3}$ & 0,00 & 0,12 & 0,09 & 0,15 & 0,08 & 0,18 & 0,12 \\
\hline $\mathrm{A}_{4}$ & 0,12 & 0,10 & 0,09 & 0,13 & 0,13 & 0,24 & 0,07 \\
\hline $\mathrm{A}_{5}$ & 0,00 & 0,07 & 0,06 & 0,10 & 0,03 & 0,31 & \\
\hline
\end{tabular}

Tablo 11. Örgütsel Koşullar Alt Kriterlerinin Ağırlıkları Ve Alternatiflere Göre Değerlendirilmesi

\begin{tabular}{|c|c|c|c|c|c|c|}
\hline \multirow[t]{2}{*}{ Ağırlıklar (w) } & 0.21 & 0.24 & 0.06 & 0.23 & 0.21 & \multirow{2}{*}{$\begin{array}{l}\text { SONUÇ } \\
\text { SKORU }\end{array}$} \\
\hline & ÖK1 & ÖK2 & ÖK3 & ÖK4 & ÖK5 & \\
\hline $\mathrm{A}_{1}$ & 0,50 & 0,51 & 0,76 & 0,53 & 0,31 & 0,58 \\
\hline $\mathrm{A}_{2}$ & 0,23 & 0,25 & 0,20 & 0,28 & 0,26 & 0,24 \\
\hline $\mathrm{A}_{3}$ & 0,09 & 0,15 & 0,04 & 0,09 & 0,21 & 0,09 \\
\hline $\mathrm{A}_{4}$ & 0,16 & 0,09 & 0,00 & 0,07 & 0,14 & 0,07 \\
\hline $\mathrm{A}_{5}$ & 0,01 & 0,00 & 0,00 & 0,04 & 0,08 & 0,01 \\
\hline
\end{tabular}

A ğırlık vektörünün bulunmasıyla birlikte daha önceki aşamalarda bulunan değerler Tablo 12'de yerine konulur ve en uygun alternatifin seçimi için her bir alt kriter değerleri ile seçeneklerin değerleri çarpılıp toplanır. Bu sonuçla birlikte seçeneklerin kriterleri ne derece etkilediği ve hangi seçeneğin tercih edileceği belirlenir.

Tablo 12. Ana-Alt Kriterler-Alternatiflerin Ağırlıkları ve Sonuç Skoru

\begin{tabular}{|c|c|c|c|c|c|c|}
\hline \multirow{2}{*}{ Ağırlıklar (w) } & $\mathbf{0 . 2 5}$ & $\mathbf{0 . 2 1}$ & $\mathbf{0 . 1 8}$ & $\mathbf{0 . 1 5}$ & $\mathbf{0 . 2 2}$ & \multirow{2}{*}{ SONUÇ SKORU } \\
\cline { 2 - 6 } & $\mathbf{M}$ & $\mathbf{B F}$ & TRU & ÇK & ÖK & $\mathbf{0 , 4 8}$ \\
\hline $\mathbf{A}_{1}$ & $\mathbf{0 , 7 1}$ & $\mathbf{0 , 0 5}$ & $\mathbf{0 , 5 5}$ & $\mathbf{0 , 4 3}$ & $\mathbf{0 , 5 8}$ & $\mathbf{0 , 2 1}$ \\
\hline $\mathbf{A}_{2}$ & $\mathbf{0 , 2 3}$ & $\mathbf{0 , 0 9}$ & $\mathbf{0 , 2 3}$ & $\mathbf{0 , 2 8}$ & $\mathbf{0 , 2 4}$ & $\mathbf{0 , 1 0}$ \\
\hline $\mathbf{A}_{3}$ & $\mathbf{0 , 0 3}$ & $\mathbf{0 , 2 0}$ & $\mathbf{0 , 1 3}$ & $\mathbf{0 , 1 0}$ & $\mathbf{0 , 0 9}$ & $\mathbf{0 , 1 0}$ \\
\hline $\mathbf{A}_{4}$ & $\mathbf{0 , 0 2}$ & $\mathbf{0 , 2 6}$ & $\mathbf{0 , 0 6}$ & $\mathbf{0 , 1 2}$ & $\mathbf{0 , 0 7}$ & $\mathbf{0 , 1 0}$ \\
\hline $\mathbf{A}_{5}$ & $\mathbf{0 , 0 1}$ & $\mathbf{0 , 4 1}$ & $\mathbf{0 , 0 3}$ & $\mathbf{0 , 0 7}$ & $\mathbf{0 , 0 1}$ & $\mathbf{0 , 1 0}$ \\
\hline
\end{tabular}

En yüksek değeri alan A1 alternatifi 0.48'lik en yüksek değerle terminallerimiz için en uygun RFID uygulaması olmuştur. İkinci olarak 0.21 değeri ile A2, diğer alternatifler ise yaklaşık olarak biri birlerine eşit değerleri almışlardır. Tablolarda belirtilen bulguların ayrıntılı değerlendirmeleri sonuç bölümünde yapılmıştır.

\section{Sonuç ve Tartışma}

Konteyner taşımacılığında ve özellikle terminallerde, RFID teknolojisi çeşitli süreçlerde uygulanabilmektedir. Terminaller bu teknolojiyi satın alırken bütçesinin önemli bir kısmını ayırmak mecburiyetinde kalmaktadır. $\mathrm{Bu}$ bağlamda terminal yöneticileri, ilgili teknolojinin uygulanacağı alanı belirlerken pek çok kriteri ve alternatifi göz önünde bulundurmak durumundadır. Bu çalışmada konteyner terminallerinde RFID sistem seçimine yönelik olarak kapsamlı bir model ortaya konmuş ve oluşturulan model çerçevesinde limanlarımıza en uygun RFID sistemi belirlenmiştir. Bu bağlamda büyük dünya limanlarında kullanılan veya kullanılması düşünülen uygulamalar belirlenmiş ve bunlardan beş tanesi oluşturduğumuz modele göre değerlendirilmiştir. Karar vericilerin dikkate alacağı veya alması muhtemel olan kriterlerin neler olabileceği araştırılmış, nitel veya nicel olan tüm kriterlerin değerlendirmeye tabi tutulmasına dikkat edilmiştir. Bu amaçla RFID teknolojisini incelemiş ve bu teknolojiyi bilen Türkiye'deki 3 büyük konteyner terminali saptanmıştır. Bu limanlarda ilgili konu ile direkt alakalı departmanlarda karar verici olarak görev ve sorumluluk alan 24 uzman ile yüz yüze görüşülmüştür. Bu görüşmeler neticesinde belirlenen kriterler ile akademik literatürde farklı sektörlere uygulanan araştırmalarda kullanılmış ve konteyner terminalciliğine uygun kriterler bir arada düşünülerek özgün bir model oluşturulmuştur. Bu bağlamda uzman görüşlerine dayanılarak 5 ana kriter başlığı ve onların altında 25 alt kriter belirlenmiştir. Belirlenen ana kriterler ve alt kriterlerden oluşturulan seçim modeli, geniş kapsamlı ve spesifik olması sebebiyle ileride yapılacak 


\section{S. Alnıpak- G. Bilen Alkan 13/4 (2021) 3889-3909}

araştırmalara çok ciddi katkıda bulunacağı düşünülmektedir. Uzmanlara uygulanan anketlerin sonucunda elde edilen veriler ile en uygun alternatifin belirlenmesinde Chang'in mertebe analizine dayalı BAHP metodu kullanılmıştır. BAHP metodu, karar verme süreci karmaşık ve belirsizlikler içeren bu tip bir problemin çözümü için en uygun metottur. Problem, kriter, alt kriter ve alternatif sayılarına göre spesifik olarak oluşturulan Excel yardımı ile çözülmüştür. BAHP metodunun modele uygulanması sonucunda; ana kriterlerin göreceli önem dereceleri incelendiğinde en uygun RFID sisteminin seçimini etkileyen ana kriterlerin önem sırası; maliyet $(0,25)$, örgütsel koşullar $(0,22)$, beklenen fayda $(0,21)$, teknik risk unsurlar1 $(0,18)$ ve çevresel koşullar $(0,15)$ olmuştur. Ana kriterlere göre alternatifler değerlendirildiğinde; beklenen fayda ana kriteri dışındaki tüm kriterlerde 1.alternatifin açık ara önde olduğu görülmüştür. Beklenen fayda ana kriterine göre ise 0.41 önem derecesi ile 5. alternatifin önde olduğu saptanmıştır. Maliyet'in alt kriterleri incelendiğinde; kuruluş aşamasındaki donanım $(0,31)$ ve yazılım $(0,22)$ maliyetlerinin, liman yöneticilerinin karar sürecinde toplam 0,53 ağırlık değeri ile en büyük önemi taşıdıkları saptanmıştır. Diğer kalemler sırası ile; süreç yenileme $(0,21)$, bakım $(0,15)$, entegrasyon $(0,10)$ ve eğitim $(0,01)$ maliyetleridir. Beklenen faydalardan; operasyonel verimlilik artışı 0,35 ağırlık değeri ile ilk sırayı alırken, artan yük güvenliği 0,30 ve artan liman güvenliği 0,29 ağırlık değerleriyle birbirlerine çok yakın önemlilikte çıkmıştır. Kurulacak RFID sisteminin terminale sağlayacağı prestij artışı'nın 0,06 ağırlık değeri ile son sırada olduğu saptanmıştır. Limanlarda uygulanacak RFID sisteminin seçiminde teknik risk unsurları'nın alt kriterlerinden güvenilirlik ve performans $(0,31)$, güvenlik $(0,30)$, ile karmaşıklık $(0,30)$ ağırlık değerleri ile biri birine yakın derecede önemli çıkarken, sağlığa etki $(0,09)$ diğer üçüne nazaran fazla önemsenmemiştir. Çevresel koşullar ana kriterini oluşturan alt kriterlerden en önemlisi; 0,24 ağırlık değeri ile kurulacak sistemin sektörel uyumluluğudur. Bu kritere çok yakın önemdeki diğer kriterler ise; ulusal ve uluslararası kanuni baskı $(0,23)$, paydaşlarla işbirliği seviyesi $(0,21)$ ve standartizasyondur $(0.21)$. Tedarikçi seviyesi $(0,06)$ ve rekabet baskısı $(0,05)$ ise diğerlerine nazaran çok gerilerde kalmaktadırlar. Örgütsel koşullar ana kriteri altındaki en önemli alt kriter; 0,29 ağırlık oranı ile limanın kurulacak sistem açısından finansal hazır olma durumudur. Bu kritere çok yakın olan diğer kriterler ise; finansal olmayan hazır olma $(0,25)$, kurulacak yeni sistemin mevcut liman sistemleri ile uyumluluğu $(0,24)$ ve üst yönetimin verdiği destektir $(0,22)$. Kurulacak yeni sisteme karşı çalışanlarca gösterilebilecek direnç ise ihmal edilebilecek kadar düşük önem seviyesindedir. Tüm ana ve alt kriterler bazında yapılan sonuç skoruna bakıldığında; ilk iki alternatif (A1 ve A2) diğer alternatiflere üstünlük kurmuştur. 1. alternatifin ağırlığ 0,48 , ikincisinin 0,21 , üçüncü, dördüncü ve beşinci alternatiflerin ağırlıkları ise 0,10 olarak hesaplanmıştır. Bu ağırlık değerlerine göre; Türk konteyner terminalleri için en uygun alternatifin; taşıуıсı araç ve sürücüsünün RFID ile kimliklendirilerek, sadece liman kapılarına konacak okuyuculardan faydalanmak olduğu saptanmıştır. İkinci alternatifte konteynerin de etiketlendirilecek olmasının yaratacağı maliyetler sıralamada geriye düşmesinde en göze çarpan nedendir. Diğer alternatiflerin (A3, A4 ve A5), E-mühür uygulaması içermeleri nedeniyle ilk iki alternatife göre çok daha az uygun olduğu düşünülmektedir. Bunun en büyük sebepleri; bu üç uygulamanın içerdiği çok yüksek maliyetler, sektörde yaratacağı karmaşık süreçler vb.dir. Yapılan analizler sonucu elde ettiğimiz bu sonuçlar araştırmanın yapıldığı dönemde ilgili teknolojiyi bilen ve konteyner limanlarında çalışan uzmanların görüşleri doğrultusunda oluşmuştur ve ilgili sonuçların karşılaştırmalarının yapılacağı bu kapsamda bir model ve çalışma bulunmamaktadır.

Perakende, lojistik ve sağlık sektörlerinde RFID teknolojisine yönelik birçok çalışma yapılmış olmasına rağmen, yaptığımız literatür taramasına göre Türkiye için konteyner terminallerinde RFID uygulaması seçim problemine yönelik araştırma ve analiz çalışması bulunmamaktadır. Bu çalışma; Türkiye konteyner terminalleri için mevcut şartlarda seçilecek en uygun RFID uygulamasını ortaya koyması açısından da önem arz etmektedir. Bu çalışma, Türk konteyner terminal yöneticilerinin -RFID özelinde- teknolojik yatırımlara yönelik karar verirken göz önünde bulundurdukları/bulundurabilecekleri kriterleri göstermesi açısından da önemlidir. Aynı zamanda, potansiyel RFID teknolojisi kullanıcılarını tanımlaması yönüyle de teknoloji şirketlerine faydalı bilgiler sunmaktadır. Çalışma bulguları, bu potansiyel kullanıcılara erişmek için uygun pazarlama stratejileri oluşturulmasında yararlı olacaktır. Pek çok lider liman işletmesi RFID teknolojisini kullanmaktadır. Bu bağlamda; kullanımı hızla artan bu teknolojiye yönelik yapılacak araştırmalar pek çok liman işletmesi için önemlidir çünkü RFID’nin pazar potansiyeli çok yüksektir. Ayrıca başlangıç periyodunda, RFID'ye karşı endüstri daha mesafeli ve kuşkucu olmasına rağmen, deneme çalışmaları kanıtlamıştır ki RFID teknolojisi operasyonel açıdan harcanan zamanı düşürmekte ve her açıdan güvenlik seviyelerini arttırmaktadır. Bu açılardan yakın gelecekte sektördeki küçük oyuncuların da bu sürecin takipçileri olması 
beklenmelidir. Fakat unutulmamalıdır ki; ancak geniş ölçekli bir yaygınlığa ulaştığında bu teknolojiden maksimum fayda sağlanabilecektir. Bu bağlamda RFID teknolojisinin konteyner taşımacılığında ve terminallerinde kullanımı hem dünyada hem de ülkemizde henüz emekleme dönemindedir. Maliyetler azalıp, donanımsal ve yazılımsal kabiliyetler yapılacak çalışmalar ile arttıkça RFID' nin kullanımı da artacaktır. Bunun yanı sıra terminallerde RFID uygulanmasına geçilmeden önce elektronik mühendislerinin, terminal sahasındaki frekans ve parazit kirliliği tespitlerini ve hangi noktalara hangi tip ekipman koyacaklarını tespit etmek amacıyla pilot çalışmalarda bulunmaları zorunluluğu vardır ve tüm bu süreçler dikkatle planlanmalıdır. Sektörde yapılacak RFID yatırımlarının artmasına bağlı olarak, araştırmacıların bilgisine sunulacak yeni bilgiler doğrultusunda; standartizasyon, sektördeki tüm tarafların sürece katılımları sonucu göğüsleyecekleri maliyetler ve sağlayacağı faydaların analizleri, teknik süreçlerin (frekanslar, sinyallerin ayrıştırılması, okuma zorlukları vb) iyileştirilmesi, konteyner taşıma zincirleri için fayda maliyet analizi, denizcilik sektörünün güvenliği ve özellikle terörizmi engelleyebilecek özgün bir RFID sistem mimarisinin tasarlanması vb. konular geleceğin araştırma konuları olacaktır. Araştırmanın yapıldığı süreçte RFID teknolojisini kullanan ve/veya araştıran limanların çok az olması ve yanısıra o dönemde limanlar için yeni bir teknolojisi olması ve kısıtlı çapta kullanılması nedenleriyle yaşanan reel veri bulamama problemi bu çalışmanın en önemli kısıtı olmuştur. Ancak yaptığımız çalışmanın ileride yapılacak çalışmalar için faydalı olacağı umulmaktadır.

\section{Kaynakça}

Abajo, V.O. (2009). Analysis of ICT solutions integration for tracking purposes in container terminal management and operation, Thesis(Master), l'Escola d'Enginyeria de Telecomunicació, Universitat Politècnica de Catalunya.

Acer, A. (2009). Bulanık AHP yöntemi ile lojistik yönetimine çözüm yaklaşımı ve bir uygulama, Tez (Y.Lisans), Sosyal Bilimler Enstitüsü, Marmara Üniversitesi.

Akcayol, M.A. ve Elmas,Ç. (2005). Sağl1k Sistemi Için Bir Akilli Kart Yazilim Uygulamasi Geliştirme, SDÜ Fen Bilimleri Enstitüsü Dergisi, 9(2), 120-125.

Alnıpak, S., Alkan, F. ve Günay, G. (2017). Veri Madenciliği, Büyük Veri Analizi Ve RFID Teknolojisi Tabanlı Konteyner Limanları, III. Ulusal Liman Kongresi, 2-3 Kasım 2017, İzmir, doi: 10.18872/DEU.df.ULK.2017.007.

Alnıpak, S. (2021). Konteyner Limanlarında RFID Teknolojisinin Kullanımına Yönelik Bir Fayda Maliyet Analizi Çalışması, OPUS Uluslararası Toplum Araştırmaları Dergisi, 18, 1614-1642.

Anand,A. ve Kulshreshtha, S. (2007). The B2C Adoption in Retail Firms in India, 2nd International Conference on Systems, ICONS, April 22-28, Martinique, 0- 7695-2807-4, 46-56.

Aydın, Ö. (2008). Bulanık AHP ile Ankara için Hastane Yer Seçimi, Dokuz Eylül Üniversitesi İktisadi ve İdari Bilimler Fakültesi Dergisi,24(2), 87-104.

Balog A., Lim J.J. ve Nettleton K. (2005). Riding the wave on ship container seal and tracking systems, Symposium on the Global Commercialization of Environmental Technologies, University of Washington, USA.

Banks, J., Hanny, D., Pachano,A.M. ve Thompson, L.G. (2007) RFID Applied, 1st ed., John Wiley \& Sons, USA, 978-0471793656.

Cho, H. ve Choi, H. (2006). LITeTag: Design and Implementation of an RFID System for IT-based Port Logistics, Journal Of Communicatıons, 1(4), 48-57.

Choi, H.R., Park, N.K., Park, B.J., Yoo, D.H., Kwon, H.K. ve Shin, J.J. (2006). Design of RFID technology-based automated gate system in a container terminal, 5th WSEAS Int. Conf. on Software Engineering, February 15-17,Madrid, Spain, 1109- 2777, 2155-2163.

Choi, H.R., Park, J.P. ve Dong, H.Y. (2007). A study on system dynamics modeling to strengthen the competitiveness of a container terminal, WSEAS International Conference on Computer Engineering and Applications, Gold Coast, Australia, January 17-19, 978-960-8457-58-4, (372-376). 
Chong, Y-L. ve Chan, T-S. (2012). Structural equation modeling for multi-stage analysis on Radio Frequency Identification (RFID) diffusion in the health care industry, Expert Systems with Applications, 39(10), $8645-8654$.

Chung, K. (2005). Secure Cargo Container and Supply Chain Management Based on Real-Time End-to-End Visibility and Intrusion Monitoring, [online], Avante International Technology, www.avantetech.com/white\%20paper\%20on\%20containerreal-time-locatingmonitoring\%20system.pdf adresinden alınmıştır.

Chwelos, P., Benbasat, I. ve Dexter, A.S. (2001). Research Report: Empirical Test of an EDI Adoption Model, Information Systems Research, 12(3), 304-321.

Crum, M.R., Premkumar, G. ve Ramamurthy, K. (1996). An assessment of motor carrier adoption, use, and satisfaction with EDI, Transportation Journal, 35(4), 44-57.

Daschkovska, K. ve Scholz-Reiter, B. (2008). Electronic Seals for Efficient Container Logistics, Dynamics in Logistics, Springer Berlin Heidelberg, Berlin, Germany, 305-312.

Dempsey, M. (2011). RFID in ports and terminals:moving towards global acceptance, [online], http://cdn.identecsolutions.com/wpcontent/uploads/2011/09/rfid_in_ports_porttechnology.pdf adresinden alınmıştır.

Denizhan, B, Yalçiner, A.Y. ve Berber, Ş. (2017). Analitik Hiyerarşi Proses ve Bulanık Analitik Hiyerarşi Proses Yöntemleri Kullanılarak Yeşil Tedarikçi Seçimi Uygulaması, Nevşehir Bilim ve Teknoloji Dergisi, 6(1), 63-78.

Englert, B., Byambajav, D. ve Parmar, A. (2007). Evaluating and improving the security of RFID tags in eSeals at the L.A. and L.B. Ports, 2nd National Urban Freight Conference, October 12-14, California, USA.

Erdal, M. (2008). Konteyner Deniz ve Liman İşletmeciliği, 1bsm., Beta Yayınları, İstanbul, 978-975-295933-0.

Finkenzeller, K. (2010). RFID Handbook: Fundamentals and Applications in Contactless Smart Cards, Radio Frequency Identification and Near-Field Communication, 3rd ed., John Wiley \& Sons, USA, 9780470695067.

Hu, L., Shi, X., Voss, S. ve Zhang, W. (2011). Application of RFID technology at the entrance gate of container terminals, Computational Logistics, 6971(1), 209-220.

Iacovou, C. L., Benbasat, I., ve Dexter, A. S. (1995). Electronic data interchange and small organizations: Adoption and impact of technology, MIS Quarterly, 19(4), 465-485.

Karkkainen, M. ve Holmstrom, J. (2002). Wireless product identification: enabler for handling efficiency, customization and information sharing, Supply Chain Management: An International Journal, 7(4), 242252.

Kavas, A., (2007). Radyo Frekans Tanımlama (RFID) Sistemleri, [online], Elektrik Mühendisliği Dergisi, http://www.emo.org.tr/ekler/ec9ec4937546363_ek.pdf?dergi=457 adresinden alınmıştır.

Kış, M. ve Kalaycı, T.E. (2008). RFID Altyapıları Ve Denizcilik Sektörü İçin Bir Açık Kaynak Uygulama, Akademik Bilişim Konferansı, Çanakkale Onsekiz Mart Üniversitesi, 30 Ocak - 1 Şubat, Çanakkale, Türkiye.

Kim, S-S., Kwak, K-S. ve Nam, K-C. (2004). A Study on the Application of RFID to Container Terminals, [online] www.esd.nankai.edu.cn/bbs/attachment.aspx adresinden alınmıştır.

Kim, S-J., Deng, G. ve Gupta, E. (2008). Enhancing cargo container security during transportation: A mesh networking based approach, IEEE International Conference on Technologies for Homeland Security, 1213 May, 978-1-4244-1977-7, 90-95.

Lee, C-P. ve Shim, J-P. (2007) An exploratory study of radio frequency identification (RFID) adoption in the healthcare industry, European Journal of Information Systems, 16(1), 712-724. 
Li, J., Wang, Y-F., Zhang, Z-M. ve Chu, C-H. (2010) Investigating Acceptance of RFID in Chinese Firms the TOE Framework, RFID Technology and Applications RFIDTA 2010 IEEE International Conference, 17-19 June, Guangzhou, China, 9781424466986, 263-280.

Lieshout, M.V., Grossi, L., Spinelli, G. (2007). RFID Technologies_Emerging Issues, Challenges and Policy Options [online], European Commission's Joint Research Centre, http://ipts.jrc.ec.europa.eu/publications/pub.cfm?id=1476 adresinden alınmıştır.

Lin, C. (2009). An Empirical Study on Organizational Determinants of RFID Adoption In the Logistics Industry, Journal of Technology Management \& Innovation, 4(1),1-7.

Ludvigsson, M. (2006). Investigation Of The RFID Technology, Thesis (Master), Department of technology, Orebro University.

Matta, V. ve Moberg, C. (2006). The Development of a Research Agenda for RFID Adoption and Effectiveness in Supply Chains, Issues in Information Systems, 7(2), 246-251.

Mcfarlane, D. ve Sheffi, Y. (2003). The impact of automatic identification on supply chain operations, The International Journal of Logistics Management,14(1),1-17.

Miragliotta, G., Perego, A. ve Tumino, A. (2007). RFID Technology In A Container Port: An Activity-Based Model To Assess Costs And Benefits, [online], http://www.niinivirta.it/upl/modules/article/attachs/20090910172125033.pdf adresinden alınmıştır.

Mullen, D. (2005). The application of RFID technology in a port, Port Technology International, 1(1), 181-182.

Narsoo,J. ve Sunhaloo, M.S. (2009). A Radio Frequency Identification (RFID) Container Tracking System for Port Louis Harbor: The Case of Mauritius, Issues in Informing Science and Information Technology, $X(2009), 127-142$.

Ngai, E., Moon, K., Riggins, F. ve Candace, Y. (2008). RFID research: An academic literature review (19952005) and future research directions, International Journal of Production Economics, 112(2), 510-520.

Ngai,E.W.T., Cheng, T.C.E., Au,S. ve Lai.K. (2007). Mobile commerce integrated with RFID technology in a contained depot, Decision Support Systems, 43 (1), 62-76.

Oranli, G. (2007). Radyo frekansıyla tanımlama teknolojisinin uygulanması kararının bulanık a nalitik hiyerarşi yöntemi ile değerlendirilmesi: Bankacılık sektöründe bir uygulama, Tez (Y.Lisans), Fen Bilimleri Enstitüsü, İTÜ.

Özmen, A.G. ve Birgün, S. (2011). Radyo Frekansı İle Tanımlama Sistemi Seçiminde Analitik Hiyerarşi Prosesi Uygulaması, Havacilık Ve Uzay Teknolojileri Dergisi, 5(1), 81-88.

Öztürk, A. (2010). Factors Affectıng Indıvıdual And Organızatıonal RFID Technology Adoptıon In The Hospitality Industry, Thesis $(P h D)$, Oklahoma State University.

Panayides, P.M. (2007). Global Supply Chain Integration and Competitiveness of Port Terminals, Ports, Cities, and Global Supply Chains, Ashgate Publishing, Hampshire, England, (18-19).

Perera, S., Mckinnon, J.L. and Harison, G.L. (2003). Diffusion of transfer pricing innovation in the context of commercialization-a longitudinal case study of a government trading enterprise, Management Accounting Research, 14(2), 140-164.

Psion Teklogix (2004). Understanding RFID and Associated Applications, [online], Psion Teklogix RFID Report, http://www.meritalk.com/uploads_legacy/whitepapers/Understanding_RFID_and_Associated_Ap plications_WhitePaper.pdf adresinden alınmıştır.

Pundir, A. (2010). Security Issues in RFID, Thesis(Master Thesis), [online], University Graduate Centre at Kjeller (UNIK), Center for Wireless Innovation Norway (CWI Norway), http://cwi.unik.no/images/Introduction_to_RFID.pdf adresinden alınmıştır.

Rizzo, F., Barboni, M., Faggion, L., Azzalin, G. and Sironi, M. (2011). Improved security for commercial container transports using an Innovative Active RFID system, Journal of Network and Computer Applications, 34(3), 846-852. 


\section{S. Alnıpak- G. Bilen Alkan 13/4 (2021) 3889-3909}

Rogers, E.M. (2003). Diffusion of Innovations, 5th ed., Free Press, New York, USA, 978-0743222099.

Schmitt,P., Thiesse, F. and Fleisch, E. (2007). Adoption and diffusion of RFID technology in the automotive industry, 15th European Conference on Information Systems, St. Gallen, Switzerland, 90-8548-014-0, 1041-1051.

Schmitt ve Michahelles (2009). Status of RFID/EPC Adoption, [online], http://www.autoidlabs.org/uploads/media/AUTOIDLABS-WP-BIZAPP-048.pdf adresinden alınmıştır.

Seymour, L., Lambert-Porter, E. ve Willuweit, L. (2007). RFID Adoption into the Container Supply Chain: Proposing a framework, 6th ISOneWorld Conference, 11-13 April, Las Vegas, USA, ISBN: 0-97721076-6, 224-240.

Sharma, A. ve Citurs, A. (2005). Radio Frequency Identification (RFID) Adoption Drivers:A Radical Innovation Adoption Perspective, 11th Americas Conference on Information Systems, Omaha, NE, USA August 1114, 9781604235531, 1213-1218.

Shih, D-H., Chiu, Y-W., Chang, S-I. ve Yen, D-C. (2008). An Empirical Study of factors Affecting RfID's Adoption in Taiwan, Journal of Global Information Management, 16(2), 58-80.

Smith, H. ve Konsynski, B. (2003). Developments in practice X: Radio frequency identification (RFID) - An Internet for physical objects, Communication of the Association for Information Systems, 12(19), 301-311.

Thomas,W. (2009). RFID in Maritime Container Logistics: A Delphi Study on Participant Specific Benefits, Hamburger Logistik Institut GmbH, Hamburg, Germany, 978-3-86850-542-9.

Tornatzky, L. G. ve Fleischer, M. (1990). The process of technological innovation, 1st ed., Lexington, MA: Lexington Books, Norfolk, USA, 9780669203486.

Torres-Barro, S.J., Fernandes, T.M., Lopez, G. ve Escudero, C.J. (2010). Maritime Freight Container Management System Using RFID, The Third International EURASIP Workshop on RFID Technology, 9396.

Tsilingiris, P.S., Psaraftis, H.N. ve Lyridis, D.V. (2006). RFID-enabled Innovative Solutions Promote Container Security,

http://www.martrans.org/docs/publ/REFEREED\%20CONFERENCES/SSE07\%20tsilingiris\%20et\%2 0al\%202007.pdf adresinden alınmıştır.

Tsilingiris P. S., Psaraftis H. N. ve Lyridis D. V. (2007). Radio Frequency Identification Technology In Ocean Container Transport, Annual Conference of the International Association of Maritime Economists, IAME, Greece, Athens.

Tuğaç, B. (2007). Radyo Frekans Kimlik Tanıma Sistemleri ile Elektronik Para Uygulamasının Gerçeklenmesi, Tez (Y. Lisans), Fen Bilimleri Enstitüsü, Yıldız Teknik Üniversitesi.

Upfold, C. ve Liu, H. (2010). Radio Frequency Identification (RFID) Adoption in the South African Retail Sector:an Investigation of Perceptions Held by Members of the Retail Sector Regarding the Adoption Constraints, The Electronic Journal Information Systems Evaluation, 13(1), 87 - 96.

Ünlü, Z., F. (2007) Tedarik zinciri yönetimi, lojistik ve taşımacılıkta bilişim teknolojileri ve uygulamaları, Tez (Y.Lisans), Fen Bilimleri Enstitüsü, İstanbul Teknik Üniversitesi.

Üstündağ, A. (2008). Radyo Frekanslı Tanıma (RFID) Teknolojisinin Tedarik Zinciri Üzerindeki Etkileri, Tez(Doktora), Fen Bilimleri Enstitüsü, İstanbul Teknik Üniversitesi.

Van Heck, E. ve Ribbers, P.M. (1999). The adoption and impact of EDI in Dutch SMEs, 32nd Annual Hawaii International Conference on System Sciences, 5-8 January, Hawai, USA, 978-0769500010, 150-160.

Wang, Y., Wang, S. ve Yang, Y. (2010). Understanding the determinants of RFID adoption in the manufacturing industry, Technological Forecasting \& Social Change, 5(77), 803-815. 
S. Alnıpak- G. Bilen Alkan 13/4 (2021) 3889-3909

Werner, S., Schuldt, A. ve Daschkovska, K. (2007). Agent-Based Container Security Systems An Interdisciplinary Perspective, INFORMATIK 2007 Informatik trifft Logistik Band 1 Beiträge der 37. Jahrestagung der Gesellschaft für Informatik e.V., Bremen, Germany,978-3-88579-206-1, 11-16.

Whitaker, J, Sunil, M. ve Krishan, M.S. (2007). A Field Study of RFID Deployment and Return Expectations, Production and Operations Management, 16(5), 599-612.

Yao, W., Chu, C-H. ve Zang, L. (2012). The Adoption and Implementation of RFID Technologies in Healthcare: A Literature Review, Journal of Medical Systems, 36(6), 3507-3525.

Yunming, P., Jingui, J. ve Yicong, L. (2007). Searching Algorithm of Container Monitoring Based on RFID, Anticounterfeiting, Security, Identification, 2007 IEEE International Workshop, https://ieeexplore.ieee.org/document/4244869 adresinden alınmıştır. 